\title{
Linkages between the South and East Asian summer monsoons: a review and revisit
}

\author{
Kyung-Ja Ha ${ }^{1,2,3} \cdot$ Ye-Won Seo ${ }^{1}$ June-Yi Lee ${ }^{2,3}{ }^{\circledR} \cdot$ R. H. Kripalani ${ }^{4} \cdot$ \\ Kyung-Sook Yun ${ }^{2}$
}

Received: 23 October 2016 / Accepted: 20 June 2017 / Published online: 5 July 2017

(c) The Author(s) 2017. This article is an open access publication

\begin{abstract}
The relationship between the South Asia monsoon (SAM) and the East Asia monsoon (EAM) possibly modulated by both external forcings and internal dynamics has been a long-standing and controversial issue in climate sciences. This study reviews their linkages as revealed in modern records and model simulations during the past, present and future, and provides a comprehensive explanation of the key mechanisms controlling the diversity of the SAM-EAM relationship. Particular attention is paid to several external forcings that modulate the relationship, including El Niño and Southern Oscillation, Indian Ocean Dipole mode (IODM), boreal summer teleconnections, and Eurasian snow extent on intraseasonal to interdecadal timescales. The major focus is placed on two integral views of the inter-connection between the two monsoon systems: one is the positive inter-correlation, which is associated
\end{abstract}

This paper is a contribution to the special issue on East Asian Climate under Global Warming: Understanding and Projection, consisting of papers from the East Asian Climate (EAC) community and the 13th EAC International Workshop in Beijing, China on 24-25 March 2016, and coordinated by Jianping Li, Huang-Hsiung Hsu, Wei-Chyung Wang, Kyung-Ja Ha, Tim Li, and Akio Kitoh.

June-Yi Lee

juneyi@pusan.ac.kr

1 Department of Atmospheric Sciences, Pusan National University, Busan, South Korea

2 Research Center for Climate Sciences, Pusan National University, Busan, South Korea

3 Department of Climate System and IBS Center for Climate Physics, Pusan National University, Busan, South Korea

4 International CLIVAR Monsoon Project Office, Indian Institute of Tropical Meteorology, Pashan, Pune 411008, India with decaying El Niño and developing Indian Ocean sea surface temperature (SST) warming anomalies; the other is the negative inter-correlation, resulting from developing El Niño and western Pacific SST cooling. The IODM mode also has a delayed impact on the negative connection by modulating Eurasian snow cover. The observed evidence reveals that the recent intensification of the negative relationship is attributable to the strengthening of the zonal SST gradient along the Indian Ocean, western Pacific, and eastern Pacific. Analysis of experiments in the fifth phase of the Coupled Model Intercomparison Project further indicates a possibility for the negative linkage to be further enhanced under anthropogenic global warming with considerable interdecadal modulation in mid and late twentyfirst century.

Keywords South Asia monsoon · East Asia monsoon · El Nino and Southern oscillation · Indian Ocean Dipole mode $\cdot$ Interannual variability $\cdot$ Interdecadal variability

\section{Introduction}

The Asian summer monsoon (ASM) consists of three subsystems: the South Asian monsoon (SAM), East Asian monsoon (EAM), and western North Pacific (WNP) monsoon (WNPM) (Wang et al. 2001; Wang and Lin 2002; Hong et al. 2005; Chang et al. 2005; Wang and Ding 2008; Clift and Plumb 2008; Lee et al. 2014a, b; Hsu et al. 2014), as shown in Fig. 1. Different from the WNPM that is an oceanic monsoon system, the SAM and EAM are continental monsoon components ( $\mathrm{Li}$ et al. 2005) and, thus, directly affect about $60 \%$ of the world populations' day-to-day life. The SAM is a part of the tropical monsoon system that essentially lies between the seasonal migration boundaries 


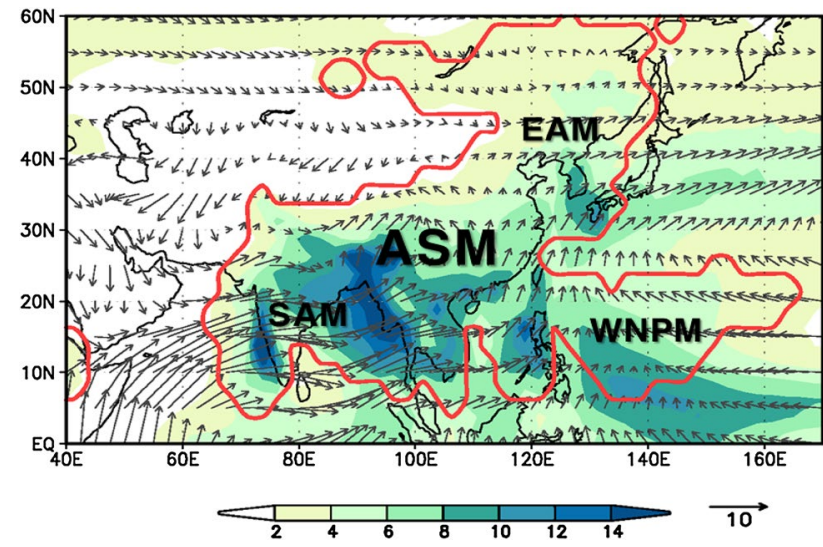

Fig. 1 The South Asian monsoon (SAM), East Asian monsoon (EAM), and western North Pacific monsoon (WNPM) in the Asian summer monsoon (ASM) system delineated by red solid line. Climatological precipitation (shading) and $850-\mathrm{hPa}$ wind (vector) during boreal summer are also presented. Units of rainfall and wind are $\mathrm{mm}$ day $^{-1}$ and $\mathrm{ms}^{-1}$, respectively

of the intertropical convergence zone (ITCZ) (An et al. 2014). On the other hand, the EAM is influenced by not only tropical monsoon and the WNP subtropical high (WNPSH) but also disturbances over mid-latitudes (Tao and Chen 1987; Kang et al. 1999). Therefore, the structure, main components, and seasonality of the EAM are largely independent of the SAM. Nonetheless, they interact with each other through energy exchange, low-frequency wave propagation, and moisture transport (Zhu et al. 1986; Zhang 1999, 2001; Ding and Wang 2005).

Many studies have been performed to ascertain linkages among the Asian monsoon subcomponents and distinct features of each subcomponent (e.g., Flohn 1958, 1960; Gao 1992; Kripalani and Kulkarni 1997, 2001; Lau and Wu 2001; Dai et al. 2002; Wang et al. 2003; Greatbatch et al. 2013; Lee et al. 2013a, b, 2017; Wei et al. 2014; Chu et al. 2017). Because the regional monsoons are modulated by diverse external forcings and internal dynamics, SAM and EAM are significantly correlated at certain times but tend to vary independently at other times (Kripalani and Kulkarni 2001; Wu 2002; Wu and Wang 2002). The aspects of the strong and weak coupling between the two regional monsoons have been respectively referred to as the "connection" and "independence" of the subsystems, respectively (Tao and Chen 1987; Qian and Yang 2000). The "connection" is seen in the in-phase or out-of-phase relationship between SAM and EAM on intraseasonal, interannual to interdecadal timescales. Recent progress in the study of the connection has been made with a focus on the impacts of external forcings, such as the El Niño and Southern Oscillation (ENSO), Indian Ocean Dipole mode (IODM), atmospheric teleconnection pattern, and Eurasian snow extent. This has provided a better understanding of the mechanism, characteristics, multi-scale variability, and major external forcings modulating the relationship (Chen et al. 2006; Ding et al. 2011; Yun et al. 2014; Wu 2017).

To better understand and elucidate variabilities in the ASM subcomponents across time scales is of great importance in the monsoon climate research community. Recent review papers have summarized and discussed the climate variations at intraseasonal to interdecadal and longer timescales (e.g., He et al. 2007; Wang et al. 2010; Ha et al. 2012, Hsu et al. 2014; An et al. 2014; Wu 2017; Lee et al. 2017). However, in spite of the previous discoveries, many features regarding the connection and independence between the two monsoon systems are not well clarified. Therefore, we review and revisit the linkages between the SAM and EAM. Note that this study only focuses on the linkages in the modern era for which there are relatively reliable observations, and excludes the studies of the pre twentieth century variability. Our main objectives are to: (1) synthesize the linkages between the SAM and EAM in the past, present, and future by reviewing previous studies; (2) better understand the physical mechanisms controlling the variety and long-term changes in the linkages, and (3) provide a comprehensive explanation of the interdecadal changes in the relationship between the two monsoon subsystems in recent decades.

\section{Description of data and experiments}

\subsection{Observation}

We used five monthly precipitation datasets as follows: (1) the Center for Climate Prediction (CPC) Merged analysis of precipitation (CMAP) with a $2.5 \times 2.5^{\circ}$ spatial resolution (Xie and Arkin 1997) for 1979-2014, (2) Global Precipitation Climatology Project (GPCP) data with a horizontal resolution of $2.5^{\circ}$ by $2.5^{\circ}$ for 1979-2014 (Huffman et al. 2001), (3) the Climate Research Unit (CRU) monthly precipitation (land only) version 3.23 of high resolution gridded data for 1901-2014 (Harris et al. 2014), (4) Seoul precipitation combined with a compiled daily rainfall dataset based on the Chukwookee records (1778-1907) (Jhun and Moon 1997) and Seoul station data obtained from the Korea Meteorological Administration (KMA) (1908-2014), and (5) All-India monsoon rainfall (AIMR) data (land only, available at http://www.tropmet.res.in) integrated from 36 stations for 1871-2014. For sea surface temperature (SST), the British Atmospheric Data Centre (BADC) Hadley Centre Sea Ice and Sea Surface Temperature (HadISST) data (Rayner et al. 2003) with a $1.0 \times 1.0^{\circ}$ spatial resolution are used. The monthly mean fields of geopotential height and wind at pressure levels are obtained from the European Centre for Medium-Range Weather Forecast (ECMWF) 
Reanalysis data. We combined datasets of the ECMWF Reanalysis data (ERA-40) from 1958 to 1978 (Uppala et al. 2005) and ECMWF Interim reanalysis data (ERA-I) from 1979 to 2015 (Dee et al. 2011).

Table 1 summarizes definition of each monsoon index used in this study. For monsoon precipitation index, the areas of SAM, EAM, and WNPM are defined as in the region of $\left(60^{\circ} \mathrm{E}-100^{\circ} \mathrm{E}, 5^{\circ} \mathrm{N}-22.5^{\circ} \mathrm{N}\right),\left(110^{\circ} \mathrm{E}-145^{\circ} \mathrm{E}\right.$, $\left.25^{\circ} \mathrm{N}-40^{\circ} \mathrm{N}\right)$, and $\left(105^{\circ} \mathrm{N}-160^{\circ} \mathrm{E}, 10^{\circ} \mathrm{N}-22.5^{\circ} \mathrm{N}\right)$, respectively. Thus, the SAM includes the Indian summer monsoon (ISM) region. The Indian region north of $22.5^{\circ} \mathrm{N}$ is not included in the definition since rainfall variability over the region tends to have different impacts to the EAM compared with that over the southern part of India. The monsoon precipitation index for the SAM (SAMP) and EAM (EAMP) is identified as area-averaged precipitation anomalies over the SAM and EAM region, respectively. The monsoon circulation index for the SAM (SAMI), EAM (EAMI), and WNPM (WNPMI) is also used: The SAMI is defined by differences between the $850-\mathrm{hPa}$ zonal wind averaged over the southern part of the SAM region $\left(40^{\circ} \mathrm{E}-80^{\circ} \mathrm{E}\right.$, $\left.5^{\circ} \mathrm{N}-15^{\circ} \mathrm{N}\right)$ and that over the northern part $\left(60^{\circ} \mathrm{E}-90^{\circ} \mathrm{E}\right.$, $20^{\circ} \mathrm{N}-30^{\circ} \mathrm{N}$ ) (Wang et al. 2004). The EAMI is defined by the intensity of zonal and meridional wind speed at 850$\mathrm{hPa}$ averaged over the EAM region $\left(127.5^{\circ} \mathrm{E}-147.5^{\circ} \mathrm{E}\right.$, $\left.32.5^{\circ} \mathrm{N}-37.5^{\circ} \mathrm{N}\right)(\mathrm{Ha}$ et al. 2005). The WNPMI is defined by differences between the $850-\mathrm{hPa}$ zonal wind averaged over the southern part of the WNP region $\left(100^{\circ} \mathrm{E}-130^{\circ} \mathrm{E}\right.$, $\left.5^{\circ} \mathrm{N}-15^{\circ} \mathrm{N}\right)$ and that over the northern part $\left(110^{\circ} \mathrm{E}-140^{\circ} \mathrm{E}\right.$, $20^{\circ} \mathrm{N}-30^{\circ} \mathrm{N}$ ) (Wang and Fan 1999). The CRU and AIMR data are over land only while GPCP and CMAP cover land and ocean.

\subsection{Model experiments}

To explain the relative role of different tropical thermal states on the SAM-EAM relationships, a series of atmospheric general circulation model (AGCM) experiments were performed using the European Centre Hamburg model (ECHAM) version 4.6 from the Max Planck
Institute for Meteorology, Hamburg, Germany. The ECHAM4.6 model is a global spectral model, with triangular truncation at wave number 42 and a 19-level hybrid sigma-pressure coordinate system. A detailed description of this model is provided in Roeckner et al. (1996). The control experiment was performed using the climatological monthly SST averaged from 1979 to 2011. The sensitivity experiments were performed using different tropical SST forcings over the Indian Ocean (IO), western Pacific (WP), and eastern Pacific (EP). The detail experimental settings with abbreviation of each experiment are presented in Table 2. Figure 2 shows SST distribution prescribed at each experiment. The SST patterns are obtained from projecting the first two empirical orthogonal function (EOF) modes of ASM precipitation variability onto SST anomalies. The first two EOF modes represent the positive and negative connection between the SAM and EAM, respectively (Sect. 3.4). For more significant results, we multiplied the regressed SST value by 2 . Each experiment was integrated for 25 years with the annual variation of SST anomalies and then the last 20-year simulation was analyzed.

To assess the SAM-EAM relationship under anthropogenic global warming, we use 9 selected coupled models' experiments in the fifth phase of the Coupled Model

Table 2 Abbreviation of individual experiments and their experimental design with specified sea surface temperature (SST) forcings in this study using ECHAM4.6

\begin{tabular}{ll}
\hline Experiment & SST forcing \\
\hline CTRL & 1979-2011 SST climatology \\
IOwm & IO warming $\left(40^{\circ} \mathrm{E}-140^{\circ} \mathrm{E}, 15^{\circ} \mathrm{S}-15^{\circ} \mathrm{N} ; \mathrm{PC} 1\right)$ \\
EPwc & El Nino to La Nina $\left(160^{\circ} \mathrm{E}-100^{\circ} \mathrm{W}, 15^{\circ} \mathrm{S}-15^{\circ} \mathrm{N} ;\right.$ \\
& PC1) \\
IOwm + EPwc & IO warming and El Nino to La Nina \\
WPcl & WP cooling $\left(40^{\circ} \mathrm{E}-140^{\circ} \mathrm{E}, 15^{\circ} \mathrm{S}-15^{\circ} \mathrm{N} ; \mathrm{PC} 2\right)$ \\
EPwm & Developing El Nino $\left(160^{\circ} \mathrm{E}-100^{\circ} \mathrm{W}, 15^{\circ} \mathrm{S}-15^{\circ} \mathrm{N} ;\right.$ \\
WPcl+EPwm & PC2) cooling and developing El Nino \\
\hline
\end{tabular}

Table 1 Monsoon region and definition of precipitation and circulation indices used in this study

\begin{tabular}{lll}
\hline & Definition & Reference \\
\hline SAM (SAMP) & $60^{\circ} \mathrm{E}-100^{\circ} \mathrm{E}, 5^{\circ} \mathrm{N}-22.5^{\circ} \mathrm{N}$ [area averaged precipitation during boreal summer (JJA)] & Yun et al. (2014) \\
EAM (EAMP) & $110^{\circ} \mathrm{E}-145^{\circ} \mathrm{E}, 25^{\circ} \mathrm{N}-40^{\circ} \mathrm{N}$ [area averaged precipitation during boreal summer (JJA)] & Yun et al. (2014) \\
& & Wang et al. (2015) \\
WNPM (WNPMP) & $105^{\circ} \mathrm{E}-160^{\circ} \mathrm{E}, 10^{\circ} \mathrm{N}-22.5^{\circ} \mathrm{N}$ [area averaged precipitation during boreal summer (JJA)] & Wang et al. (2015) \\
SAMI & $\mathrm{U} 850\left(40^{\circ} \mathrm{E}-80^{\circ} \mathrm{E}, 5^{\circ} \mathrm{N}-15^{\circ} \mathrm{N}\right)-\mathrm{U} 850\left(60^{\circ} \mathrm{E}-90^{\circ} \mathrm{E}, 20^{\circ} \mathrm{N}-30^{\circ} \mathrm{N}\right)$ & Wang et al. (2004) \\
EAMI & $(\mathrm{U} 8502+\mathrm{V} 8502) 1 / 2\left(127.5^{\circ} \mathrm{E}-147.5^{\circ} \mathrm{E}, 32.5^{\circ} \mathrm{N}-37.5^{\circ} \mathrm{N}\right)$ & Ha et al. (2005) \\
WNPMI & $\mathrm{U} 850\left(100^{\circ} \mathrm{E}-130^{\circ} \mathrm{E}, 5^{\circ} \mathrm{N}-15^{\circ} \mathrm{N}\right)-\mathrm{U} 850\left(110^{\circ} \mathrm{E}-140^{\circ} \mathrm{E}, 20^{\circ} \mathrm{N}-30^{\circ} \mathrm{N}\right)$ & Wang and Fan $(1999)$ \\
\hline
\end{tabular}

Except CRU which is just available over land, we use both land and ocean grids to calculate the indices 
Fig. 2 Temporal evolution of sea surface temperature (SST) forcing (unit: ${ }^{\circ} \mathrm{C}$ ) prescribed in the a IOwm, b EPwc, $\mathbf{c}$ IOwm + EPwc, $\mathbf{d}$ WPcl, $\mathbf{e}$ EPwm, and $\mathbf{f} \mathrm{WPcl}+\mathrm{EPwm}$ experiment, averaged over the $15 \mathrm{~S}-15 \mathrm{~N}$ region. The SST forcing indicates the difference in SST between each experiments and CTRL (a) $10 \mathrm{wm}$

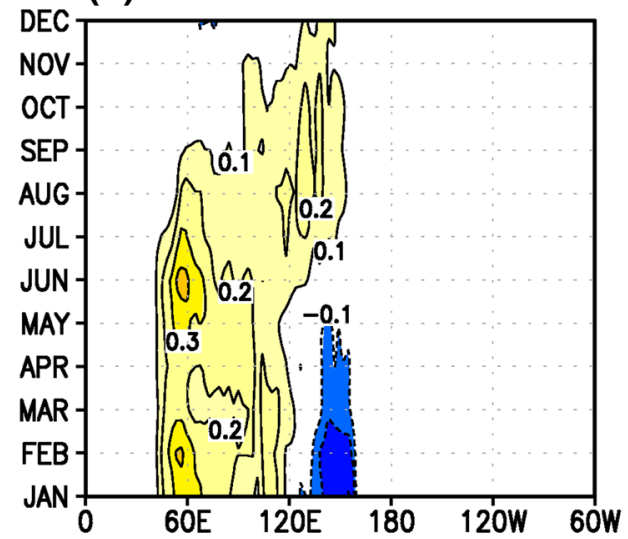

(b) EPwc

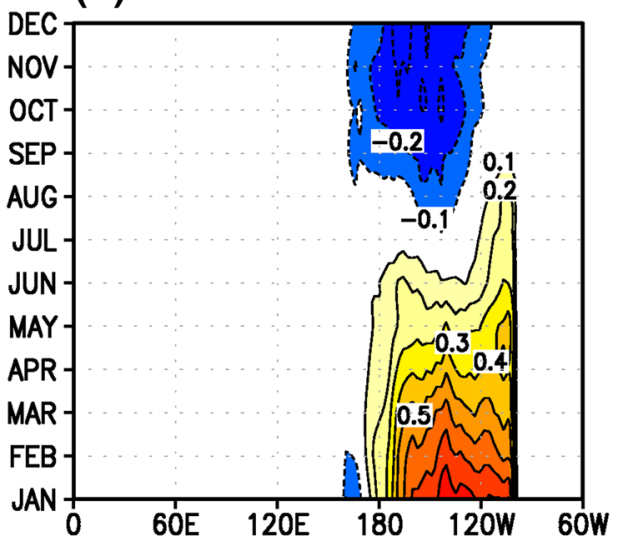

(c) $10 w m+E P w c$

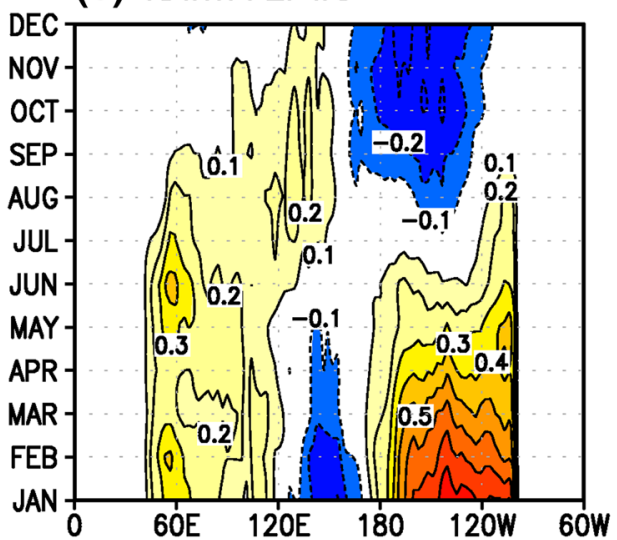

(d) $\mathrm{WPcl}$

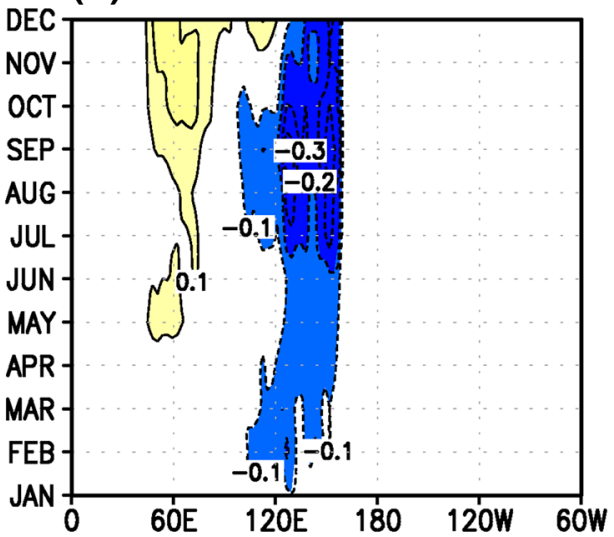

(e) EPwm

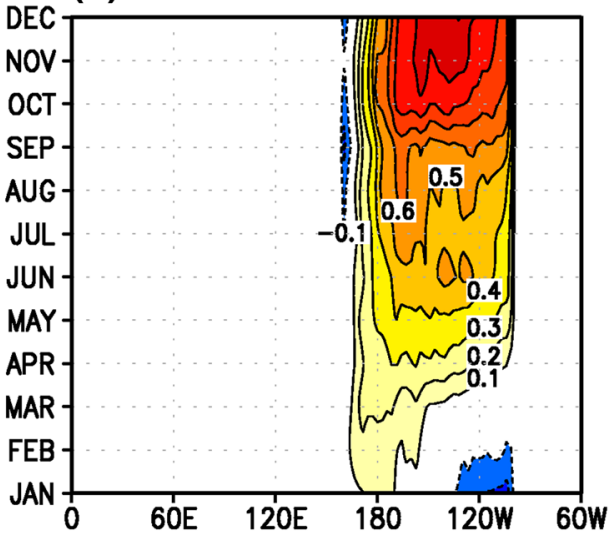

(f) $\mathrm{WPcl}+\mathrm{EP} w \mathrm{~m}$

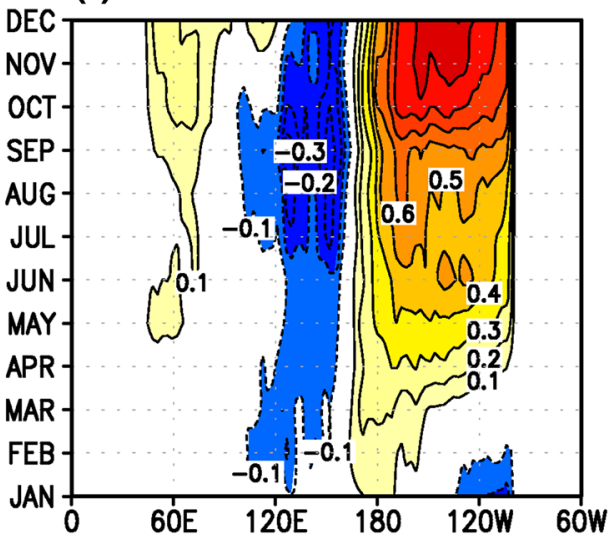

Intercomparison Project (CMIP5) based on Preethi et al. (2017). Two experiments are investigated. One is the historical run from 1850 to 2005 and the other is the Representative Concentration Pathway (RCP) 4.5 from 2006 to 2100 . The RCP 4.5 run assumes that radiative forcing will increase and then stabilize at about $4.5 \mathrm{Wm}-2$ after
2100 and is chosen as a central scenario in CMIP5 (Taylor et al. 2012). The CMIP5 models have been downloaded from http://cmip-pcmdi.llnl.gov/cmip5. Refer Preethi et al. (2017) for detail information of 9 CMIP5 model used in this study. 
Fig. 3 Climatological pentad (5-day) mean precipitation rate $\left(\mathrm{mm} \mathrm{day}^{-1}\right)$ averaged over a the SAM sector $\left(60^{\circ} \mathrm{E}-100^{\circ} \mathrm{E}\right)$ and $\mathbf{b}$ the EAM sector $\left(110^{\circ} \mathrm{E}-145^{\circ} \mathrm{E}\right)$. The data used are derived from GPCP for the period of 1979-2014. This figure is adapted from Chang et al. (2005)

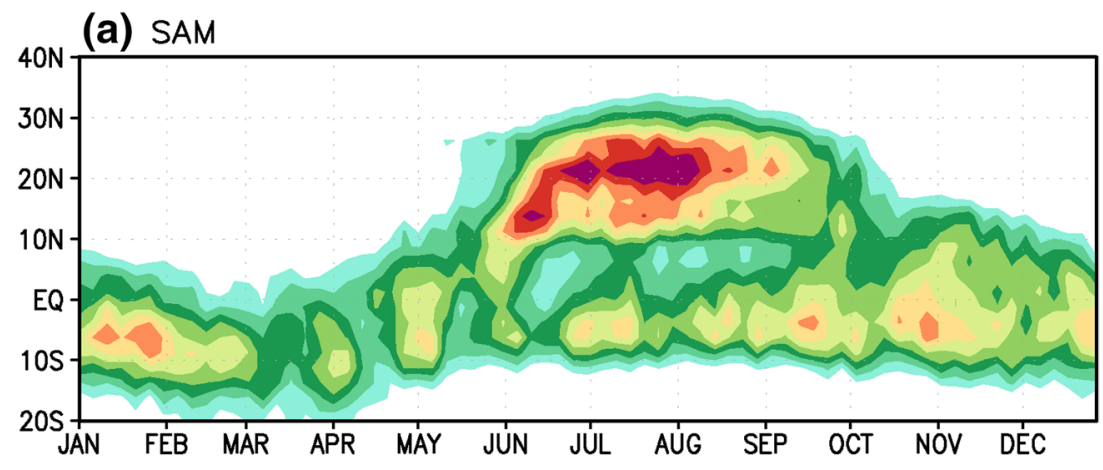

(b) EAM

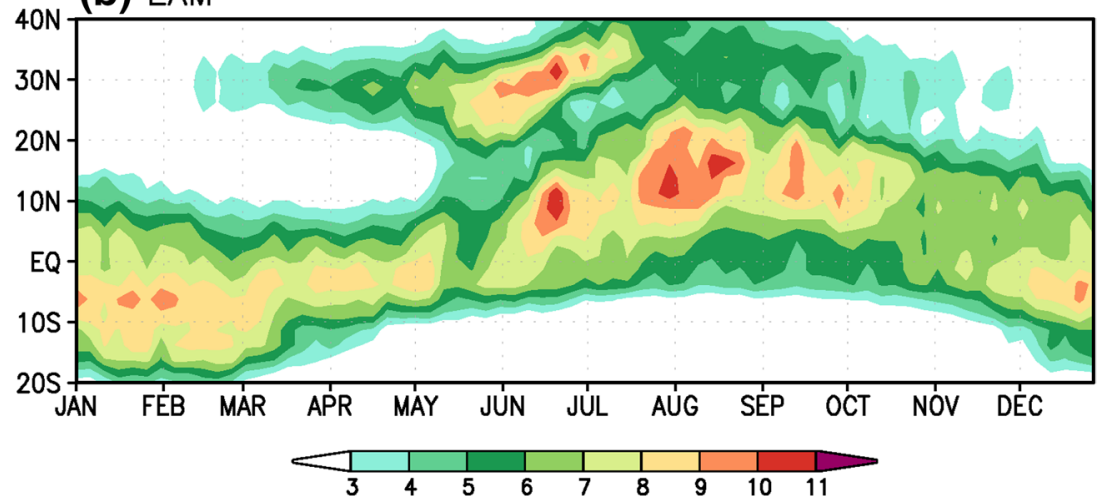

\section{SAM and EAM}

\subsection{Climatological characteristics}

Figure 3 shows the climatological 5-day mean precipitation over the SAM and EAM. Along the SAM sector $\left(60^{\circ} \mathrm{E}-100^{\circ} \mathrm{E}\right)$, a gradual northward propagation of the rain band from the Southern Hemisphere $(\mathrm{SH})$ to the Indian subcontinent is evident from April to July and a retreat to the south is evident after early September. The Himalayas and Tibetan Plateau block the northward migration of rain band around $30^{\circ} \mathrm{N}$. On the contrary, along the EAM sector $\left(110^{\circ} \mathrm{E}-145^{\circ} \mathrm{E}\right)$, the seasonal variations undergo a sudden shift in rainfall from the $\mathrm{SH}$ to the Northern Hemisphere $(\mathrm{NH})$ tropics and from $\mathrm{NH}$ tropics to the EAM region during May. From May to August, the rain band slowly migrates northward in the NH subtropics and EAM region reaching up to $25^{\circ} \mathrm{N}$ and $40^{\circ} \mathrm{N}$, respectively. Another noteworthy difference in the two longitude bands is the prominent presence of the ITCZ in the SH $\left(10^{\circ} \mathrm{S}-\right.$ eq. $)$ over the Indian longitudes (Fig. 3a) but its near absence over the WP between July and September (Fig. 3b). Over the Indian longitudes, an enhanced (suppressed) convection over the oceanic equatorial zone is associated with suppressed (enhanced) convection over the continental region $\left(15^{\circ} \mathrm{N}-25^{\circ} \mathrm{N}\right.$ : Sikka and Gadgil 1980). Furthermore, while the northward progression of the oceanic convective zone, the ITCZ, reaches up to $30^{\circ} \mathrm{N}$ over the Indian longitudes, it only reaches up to $20^{\circ} \mathrm{N}$ over the WP region.

\subsection{Interannual to interdecadal linkages: a review}

The connection between the SAM and EAM has been recognized at timescales ranging from intraseasonal (e.g., Kripalani et al. 1997; Ding and Wang 2007) to interannual (e.g., Krishnan and Sugi 2001; Wu 2002; Wu et al. 2003; Ding and Wang 2005) to interdecadal (e.g., Kripalani and Kulkarni 2001; Yun et al. 2014). In many cases of previous studies, the SAM is defined by all Indian monsoon rainfall and EAM defined by either North China or Yangtze River/Korea/Japan. Thus, it should be careful to interpret the SAM-EAM relationship from previous papers. In this study, EAM mainly refers the region of Yangtze River/ Korea/Japan. In general, rainfall variability over North China has a negative relationship with that over EAM defined here.

At interannual timescales, it has been reported that the SAM has an out-of-phase (negative) relationship with the EAM but an in-phase (positive) relationship with the rainfall variability over northern China in the modern record (Guo and Wang 1988; Kripalani and Singh 1993; Hu and Nitta 1996; Kripalani et al. 2002; Kim et al. 2002; Wu 2002; Wu et al. 2003; Ding and Wang 2005; Ding et al. 2011; Lee et al. 2013b, 2014a) and in proxy record during Holocene (An et al. 2000; Chen et al. 
2008; Wang et al. 2010). Several studies have argued that the variability of the SAM drives that of the EAM (e.g., Wu 2002; Wu et al. 2003; Greatbatch et al. 2013). Zhang $(1999,2001)$ claimed that the impact of the SAM on the rainfall over North China is through the transportation of water vapor from the Indian region. The Key mechanisms on the connection proposed are (1) the east-west shift of the South Asian High (SAH) (Tao and Zhu 1964; Wei et al. 2014), (2) modulation by the WNPSM (Cao et al. 2012; Chowdary et al. 2013; Bandgar et al. 2014), and (3) a mid-latitude circulation pattern over the Asian continent (Krishnan and Sugi 2001; Wu 2002; Wu et al. 2003; Greatbatch et al. 2013). The SAM tends to affect the EAM via the east-west shift of the SAH exhibiting the tripolar pattern of the summer rainfall anomalies over China (Wei et al. 2014). On the contrary, some others have claimed possibility for the EAM or WNPSM to modulate the SAM variability. Jin and Chen (1982) suggested that the EAM system significantly affects the SAM system, and that the SAM does not significantly affect the EAM system. Chowdary et al. (2013) and Bandgar et al. (2014) also suggested that the WNPSH influences the SAM. By using an index to quantify the interface between the SAM and EAM, Cao et al. (2012) found that the WNPSH as a major factor for the EAM variability, plays an important role in the negative relationship between the SAM and EAM. In addition, intrinsic atmospheric circulation pattern over the mid-latitude may play a certain role on the connection, particularly over land (Wu 2002; Wu et al. 2003; Greatbatch et al. 2013). It is important to further note that the connection is not steady throughout the modern period. For example, the correlation between Indian and North China summer rainfall experienced a significant change around the late 1970s (Wu 2017). Their positive correlation was very high reaching up to 0.8 during 1950s and 1960s but has decreased considerably after the late 1970s.

At interdecadal timescales, the SAM and EAM rainfall has exhibited alternate regimes of above- and below-normal rainfall with lasting time scale of about 30 years. The turning points between regimes for China follow those of India a decade later. Kripalani and Kulkarni (2001) suggested that the SAM plays a role in modulating the decadal variability of the summer monsoon rainfall over North China. However, a recent study of Li and Leung (2013) showed that the interdecadal summer precipitation variability in China is related to the Arctic spring warming. It has been also recently reported that the rainfall over the Indian monsoon rainfall, particularly over the northeast part, and northern China has a declining trend (Bollasina and Nigam 2008; Bollasina et al. 2011) but that over the Yangzte-Huai River valley and South Korea has an increasing trend (Kripalani et al. 2002; Choi et al. 2010; Preethi et al. 2016).
The difference in the trends has led to an intensification of the SAM-EAM contrast during last three decades (Yun et al. 2014).

\subsection{Interannaul to interdecadal linkages: a revisit}

The above reviews on previous studies indicate that deficiencies remain in understanding the SAM-EAM relationship. Thus, this study revisits this issue and investigates the SAM-EAM relationship with existing long-term datasets available in the modern record. We use both monsoon rainfall and circulation indices for the analysis of the relationship. Analysis of the several datasets reveals that the SAM-EAM rainfall relationship on interannual timescale is generally not significant and exhibits notable interdecadal variation (Fig. 4). In addition, different datasets and variables tend to provide different results.

We first analyze the AIMR and Seoul rainfall, those are the two longest observed rainfall records, as the proxy of SAM and EAM, respectively. It is found that the relationship between two rainfall data on interannual timescale is not stable in the past. The 17-year moving correlation coefficient between the AIMR and Seoul rainfall for the last 144 years of 1871-2014 indicates that their negative relationship is statistically significant just during 1930s and 1940s (black line in Fig. 4a). In addition, significant negative value is not shown in the moving correlation coefficient between the AIMR and EAMP obtained from CRU (blue line in Fig. 4a) during 1901-2014. Although not significant, there is an increasing trend in the negative correlation during the last two decades. If we substitute the EAMP calculated from either GPCP (red line) or CMAP (green line) data for Seoul rainfall, the negative correlation has appeared to be significant during the last 30 years.

We then analyze the EAMP and SAMP relationship using several datasets with available time period including CRU (land only), GPCP and CMAP (both land and ocean). Analysis of the CRU land rainfall data indicates that the EAMP and SAMP relationship has exhibited considerable interdecadal variation for the 114 years of 1901-2014 and is significantly negative in 1990s and 2000s (Fig. 4b). The negative relationship during recent two decades (1990-2010) is also noted in the SAMP-EAMP correlation coefficient of -0.28 based on GPCP data. However, the correlation obtained from CMAP data is just -0.13 and insignificant.

Taking into account the inconsistent relationship among datasets and variables, we calculate the temporal correlation coefficient ( $r$ ) among the monsoon precipitation and circulation indices for 1990-2010 (Table 3) and note several interesting aspects. For circulation index, ERA data is used and for precipitation index, GPCP and CMAP (value in parentheses) data are used. First, the EAMP-EAMI 
Fig. 4 17-year window sliding temporal correlation coefficients (TCC) between a all Indian monsoon rainfall (AIMR) and Seoul rainfall (black line) for 1871-2014 and b SAMP and EAMP using CRU (blue line) for 1901-2014. In a and b, correlations with EAMP obtained from GPCP (red line) and CMAP (green line), respectively, are also shown. The blue line in a indicates the TCC between AIMR and EAMP obtained from CRU for 1901-2014. The definition of each monsoon precipitation index is given at Sect. 2.1 in the main text

\section{(a) All India monsoon rainfall}

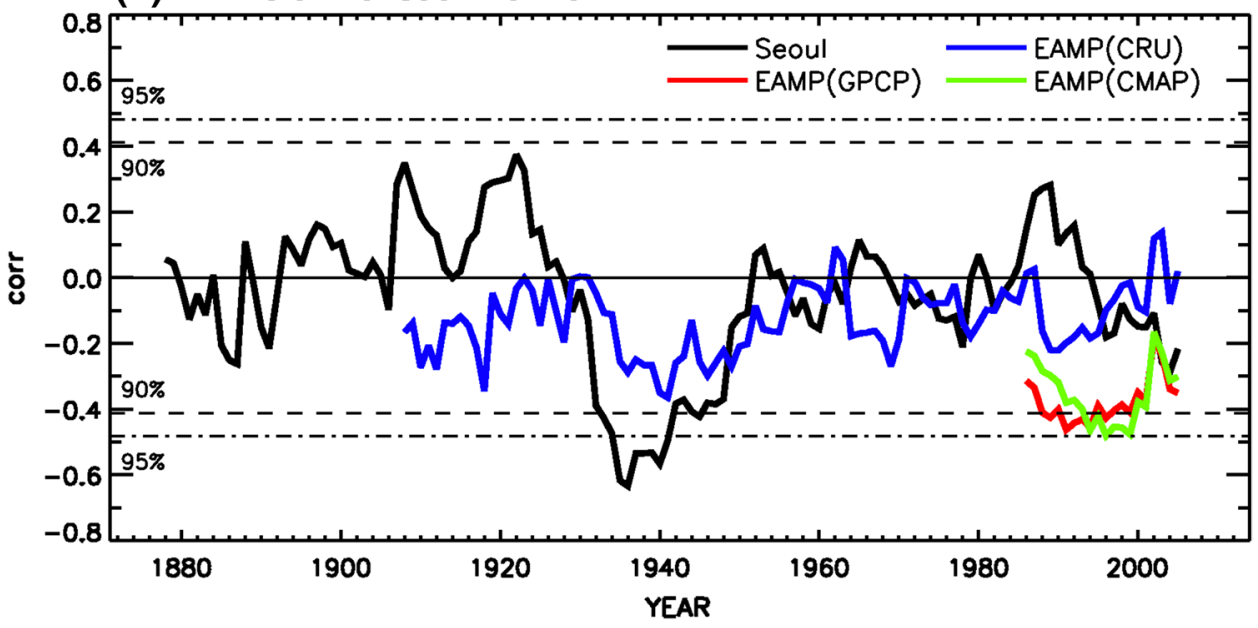

(b) EAMP \& SAMP

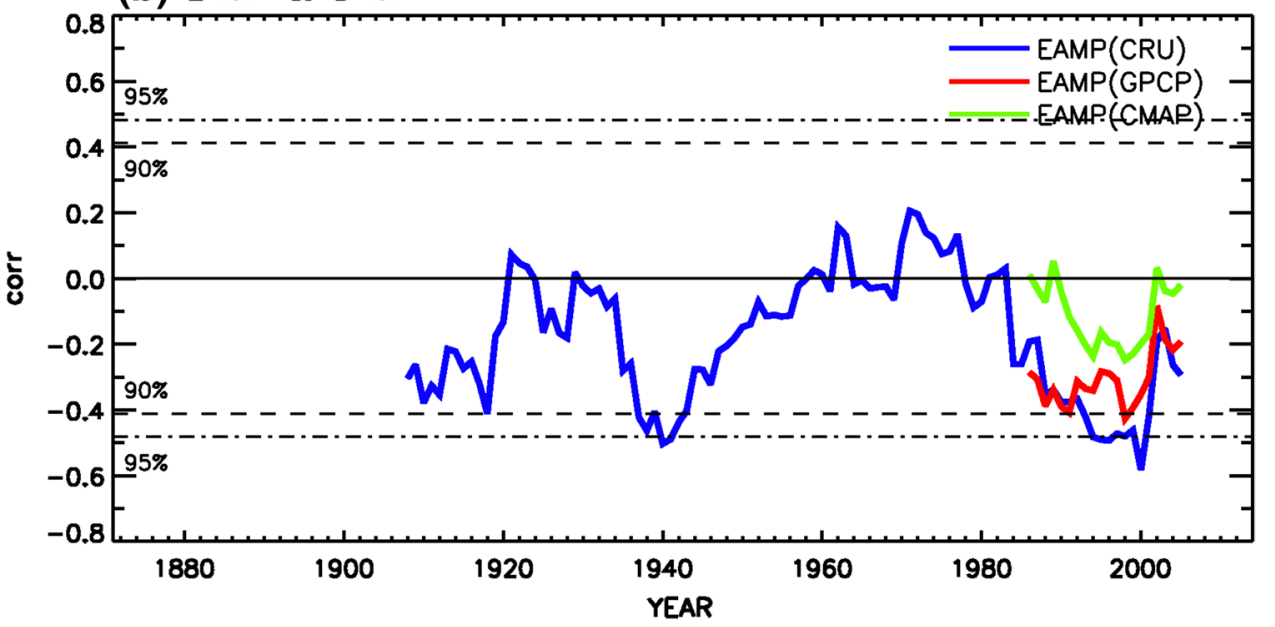

Table 3 Temporal correlation coefficients (TCCs) among South Asian monsoon (SAM) and East Asian monsoon (EAM) rainfall and circulation indices for the period of 1979-2013

\begin{tabular}{llll}
\hline & SAMI & WNPMI & EAMI \\
\hline SAMP & $\mathbf{0 . 5 7}(\mathbf{0 . 5 7})$ & $-0.31(-\mathbf{0 . 5 3})$ & $-0.25(-0.04)$ \\
EAMP & $-0.34(-0.30)$ & $\mathbf{- 0 . 6 0}(-\mathbf{0 . 5 2})$ & $\mathbf{0 . 7 7}(\mathbf{0 . 7 0})$ \\
\hline
\end{tabular}

Refer Table 1 for the definition and region for each index. For the calculation, we use GPCP (CMAP in parentheses) rainfall and ERA circulation data. The correlation coefficients in bold indicate values that are significant at the $95 \%$ confidence level

correlation is much higher than the SAMP-SAMI correlation during the recent period. While the SAMI has a moderate negative relationship with EAMP, the EAMI shows an insignificant negative correlation with SAMP. Second, WNPMI is highly correlated with EAMP $(\mathrm{r}=-0.60$ and -0.52 using GPCP and CMAP, respectively). Further analysis indicates that the role of WNPM circulation (or WNPSH) on both SAM and EAM has enhanced during recent few decades (not shown). This result strongly supports the previous finding of Cao et al. (2012) that the WNPSH plays an important role in the SAM-EAM connection.

To verify spatial consistency in the SAM-EAM relationship, we analyze spatial distribution of the correlation coefficients between rainfall time series over the entire Asia including ocean and the EAMP index for 1901-2014 and for 1979-2014 (Fig. 5). It is noted that the EAMP index well represents the interannual variability of monsoon rainfall over the entire EAM region used in this study for not only the recent few decades, but also the last 114 years. On the other hand, its relationship over the SAM region is not stable and spatially varying. The EAM has a positive correlation (in-phase relationship) over some part of SAM region defined in this study whereas a negative correlation (out-of-phase relationship) over the northern part of India and Myanmar, north of $15^{\circ} \mathrm{N}$. Thus, there may be cancellation of relationship when the SAMP index is calculated by averaging summer rainfall over the SAM region. 
(a) $1901-2014$ (CRU)

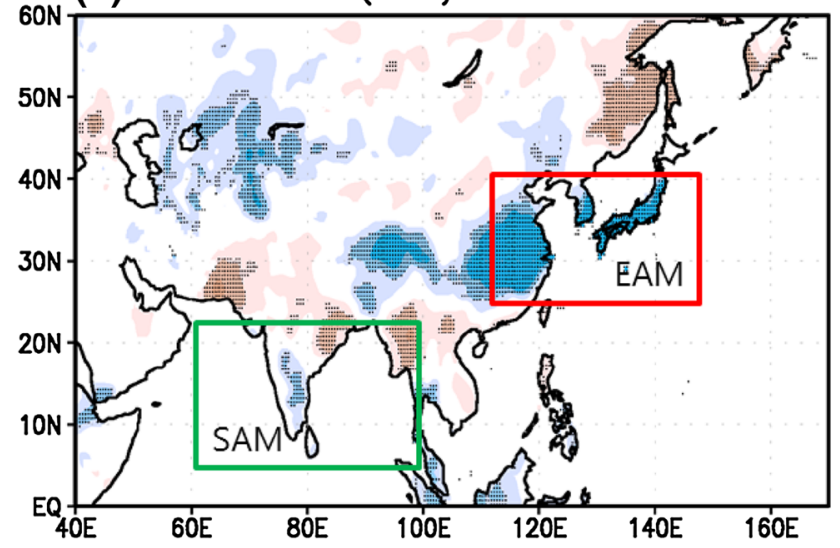

(b) $1979-2014$ (CRU)

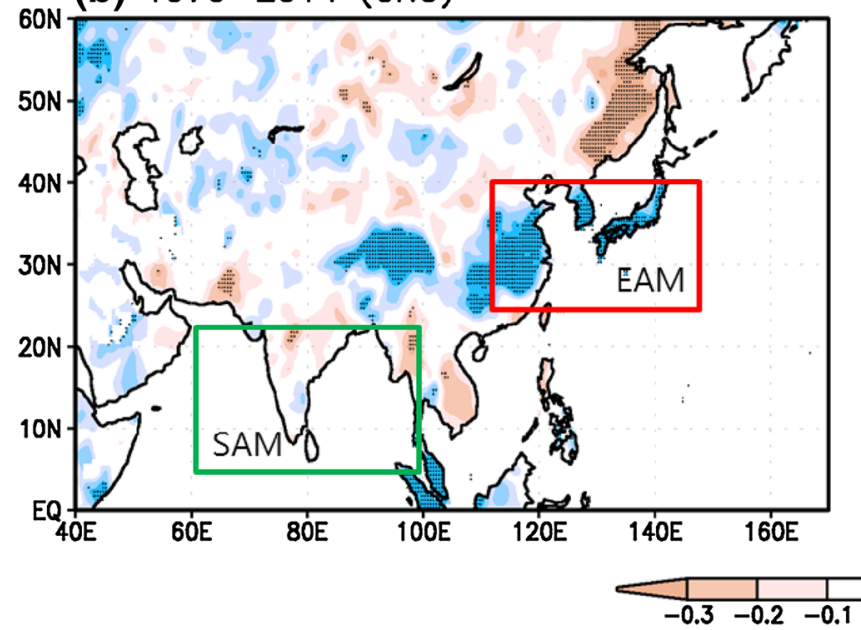

(c) $1979-2014$ (GPCP)

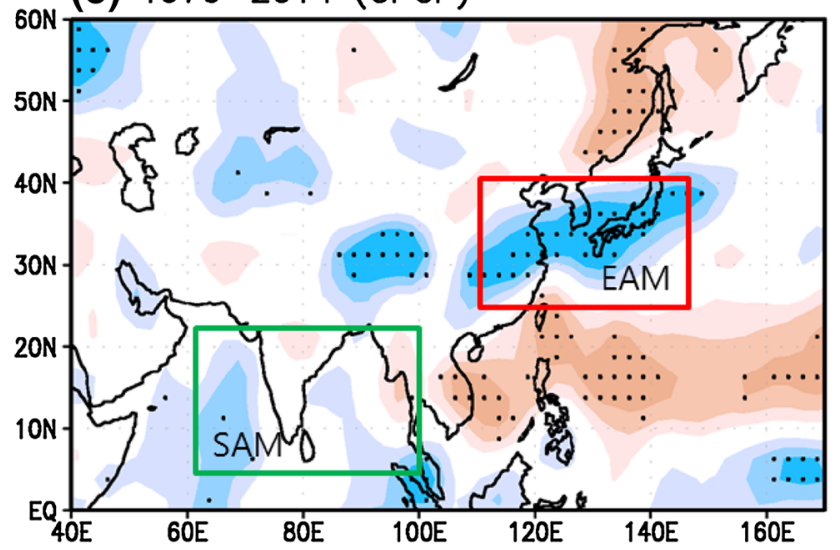

(d) $1979-2014$ (CMAP)

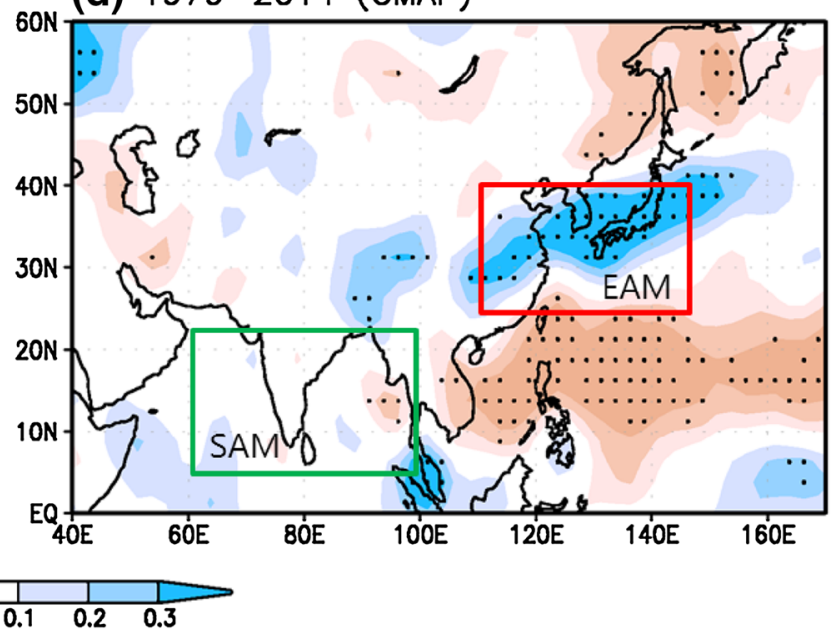

Fig. 5 TCCs between summer monsoon rainfall at each grid point over Asia and EAMP $\left(110^{\circ} \mathrm{E}-145^{\circ} \mathrm{E}, 25^{\circ} \mathrm{N}-40^{\circ} \mathrm{N}\right)$ during a $1901-$ 2014 and b 1979-2014, respectively, obtained from CRU. Those calculated from GPCP and CMAP during 1979-2014 are shown in $\mathbf{c}$ and d, respectively. TCCs statistically significant at $95 \%$ confidence level are shown with dot marks. The red and green boxes denote the East Asia and South Asia region

variables. It is suggested that the WNPM/WNPSH system may play a role in modulating the SAM and EAM relationship during recent few decades. The next subsection discusses the reason why the SAM-EAM negative relationship previously noted is not clearly detected in this study.

\subsection{Connections associated with the major modes of ASM variability}

In this section, we suggest that the in-phase and out-ofphase relationships of SAM-EAM appear in association with the two major modes of the ASM variability (Yun et al. 2014; Wang et al. 2015). To investigate the dominant modes of the ASM variability, EOF analysis is applied to boreal summer (JJA) precipitation over the entire Asia region $\left(50^{\circ} \mathrm{E}-150^{\circ} \mathrm{E}\right.$, eq. $\left.-50^{\circ} \mathrm{N}\right)$ for $1979-2015$ using CMAP data (Fig. 6). 
Fig. 6 Spatial patterns and time series of $\mathbf{a}$ the first and $\mathbf{b}$ the second EOF mode of the precipitation during boreal summer (JJA) obtained from CMAP. The EOFs are computed using data from the geographic region $\left(\mathrm{Eq}-50^{\circ} \mathrm{N}, 50^{\circ}-150^{\circ} \mathrm{E}\right)$ with covariance matrix show in the figures. The green dashed line in right panels is PC time series obtained from GPCP

\section{Principal mode of precip anomaly ( CMAP )}

(a) 1 st mode (20.06\%)

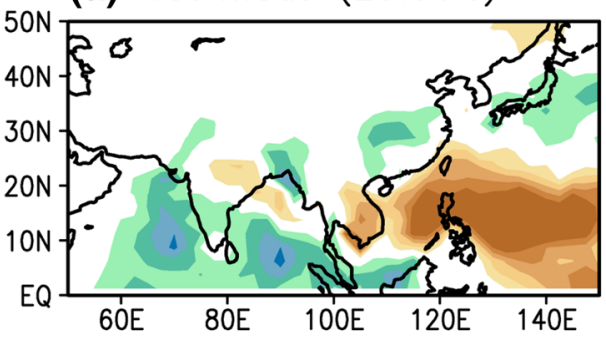

(b) 2nd mode (12.56\%)

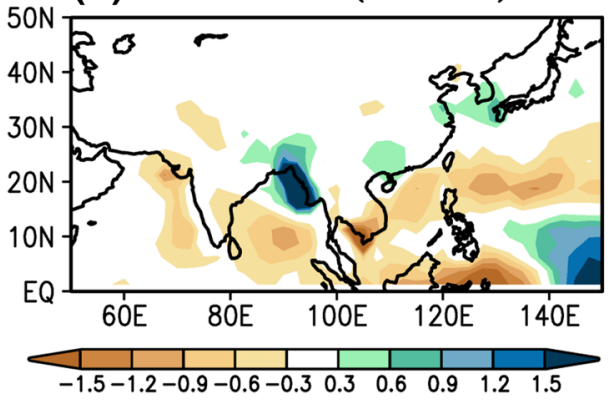

$\mathrm{PC}$ time series

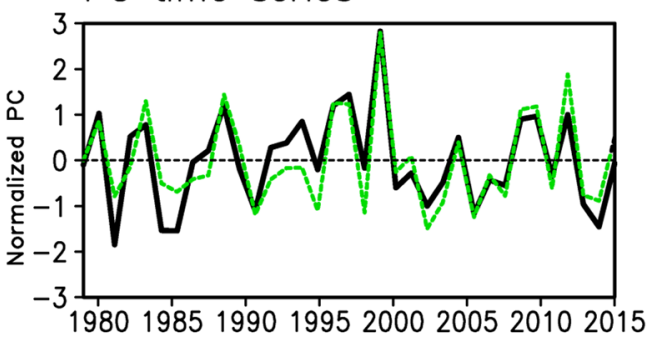

PC time series

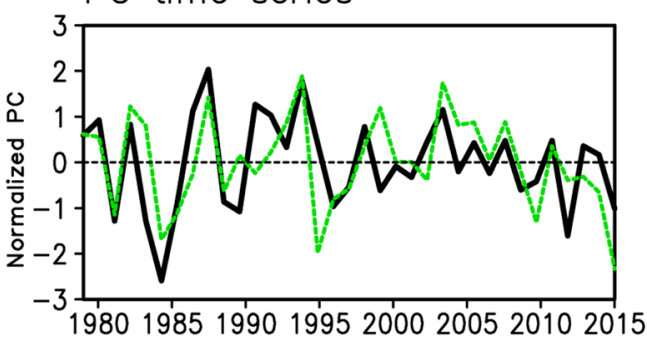

Table 4 TCCs between the first two EOF modes and Monsoon indices using ERA for the period of 1979-2013

\begin{tabular}{|c|c|c|c|c|c|}
\hline & \multicolumn{2}{|l|}{ GPCP } & \multicolumn{3}{|l|}{ ERA } \\
\hline & SAM & EAM & SAMI & EAMI & WNPMI \\
\hline $\mathrm{PC} 1$ & 0.36 & 0.44 & 0.09 & 0.48 & -0.88 \\
\hline PC2 & -0.31 & 0.18 & -0.29 & 0.35 & 0.29 \\
\hline
\end{tabular}

The bold values indicate the TCC is statistically significant at the 95\% confidence level

The first (EOF1) and second EOF mode (EOF2) explain approximately 20.06 and $12.56 \%$, respectively, of the total ASM variance. The EOF1 features the zonally oriented wet and dry belts in the subtropics. During its positive phase, precipitation anomaly is positive over the Yangtze River Valley, around Japan $\left(\sim 35^{\circ} \mathrm{N}\right)$, and the western Arabian Sea, but negative over the WP and the South China Sea (Fig. 6a). In contrast, the main special characteristics of EOF2 include (1) the negative precipitation anomaly belt over the WP, Maritime Continent (MC), and the southern Bay of Bengal and positive anomaly over the northern Bay of Bengal, equatorial WP, and southern Korea during its positive phase (Fig. 6b). Therefore, the EOF1 provides the positive relationship between the EAM and SAM, but the EOF2 is responsible for their negative correlation. The first two modes are not completely statistically separated each other but they are independent of the third EOF mode (not shown). These two major modes correspond to those of Liu et al. (2008), Sun et al. (2010) and Wang et al. (2015). The two modes together explain more than $20 \%$ of the total precipitation variability over the SAM and EAM.

We investigate the association of the first two major ASM modes with regional monsoon rainfall/circulation indices. Table 4 presents the correlation coefficients between the first and second principal component time series and monsoon indices. In terms of precipitation, the EOF1 has a significant positive correlation with both SAMP and EAMP but the EOF2 exhibits a moderate negative correlation with the SAMP. On the other hand, in terms of circulation, the EOF1 and EOF2 have a significant positive correlation with the EAMI and the EOF2 and SAMI has a moderate negative correlation. It is interesting to note that the EOF1 time variation is highly correlated with the WNPMI $(r=-0.88)$. To sum up, the in-phase SAM and EAM relationship tends to be associated with the EOF1 when they have out-of-phase relationship with WNPM. However, the EOF2 provides moderate out-of-phase relationship of the two monsoon systems.

\section{Physical basis of the relationship}

\subsection{Developing ENSO}

Many previous studies have paid more attention to the negative SAM-EAM relationship than their positive connection (Kripalani and Singh 1993; Hu and Nitta 1996; Kripalani et al. 2002; Kim et al. 2002; Ding and Wang 2005; Ding et al. 2011; Lee et al. 2013a, b). The negative connection is primarily attributable to the developing 
PC1

(a) $\operatorname{DJF}(-1)$

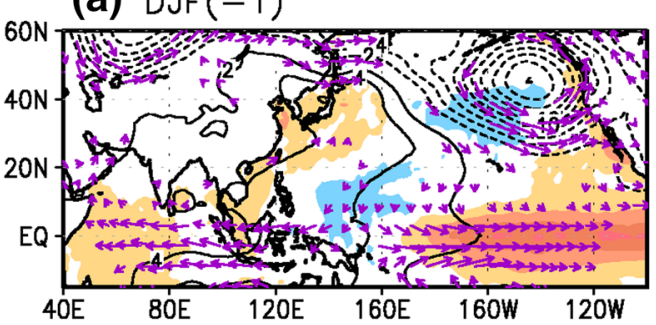

(b) MAM

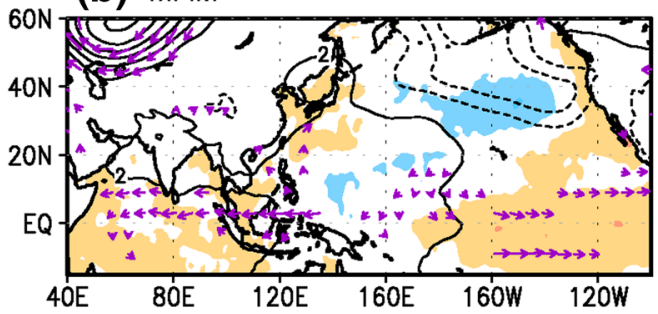

(c) JJA

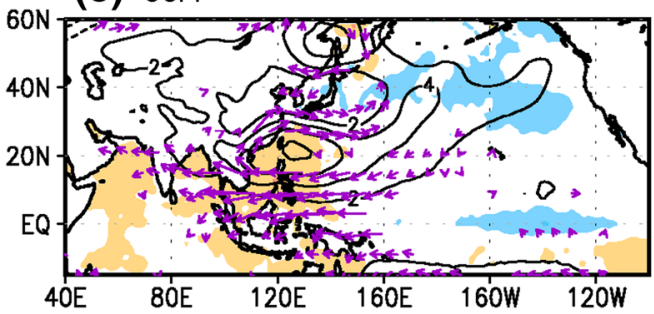

(d) $\mathrm{SON}$

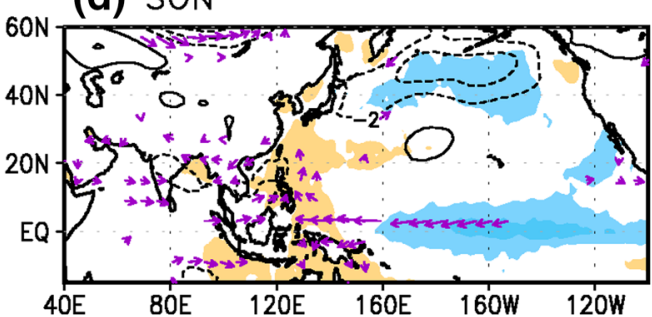

(e) DJF

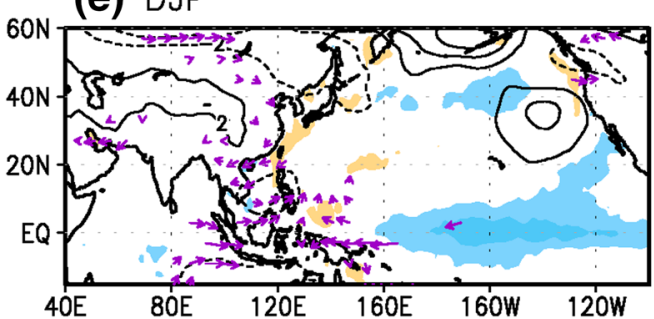

Fig. 7 Time evolution of the regressed anomaly fields of SST from HadiSST (shading, unit: ${ }^{\circ} \mathrm{C}$ ) and geopotential height at 850 -hPa from ERA-I (contour, unit: $\mathrm{m})$ against PC1 $(\mathbf{a}-\mathbf{e})$ and PC2 $(\mathbf{f}-\mathbf{j})$ of EOF

phase of the ENSO (Hu et al. 2005; Wang et al. 2015) and/or accomplished through a wave-type anomalous circulation over mid-latitude Asia (e.g., Kripalani et al. 1997; Krishnan and Sugi 2001; Wang et al. 2001; Wu 2002; Wu et al. 2003; Ding and Wang 2005, 2007;
PC2

(f) $\operatorname{DJF}(-1)$

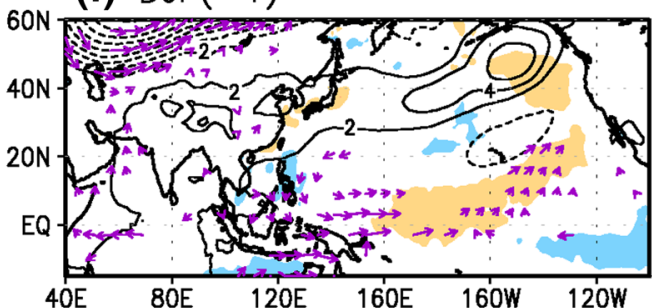

(g) MAM

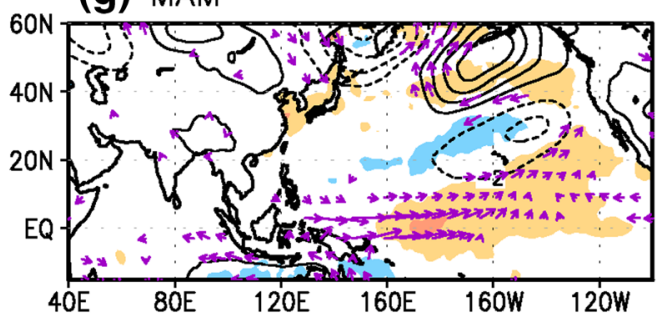

(h) JJA

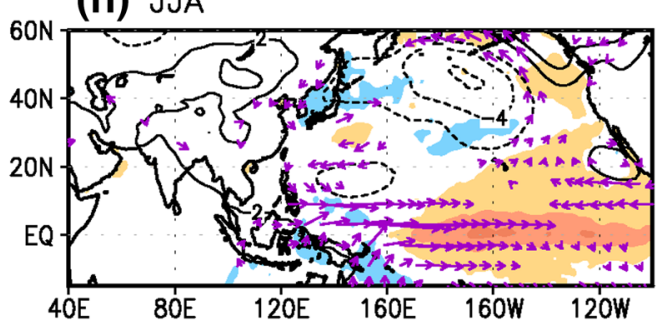

0.7
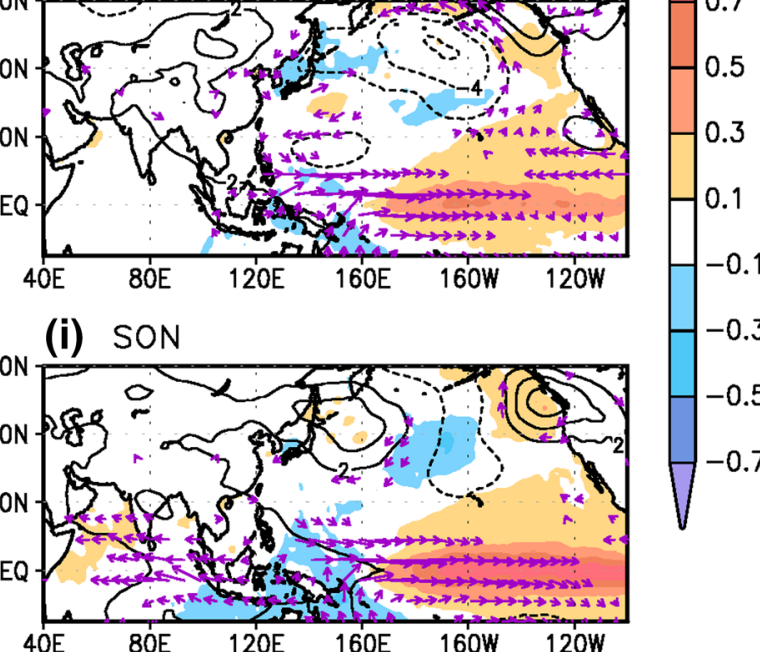

$-0.3$

$-0.5$

$-0.7$

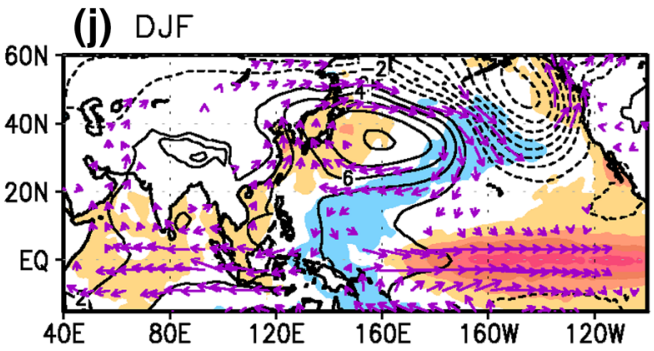

during 1979-2015. The vector denotes the regressed 850-hPa horizontal wind anomaly significant at the $95 \%$ confidence level

Ogasawara and Kawamura 2008 and many others). It is shown from Fig. $7 \mathrm{f}-\mathrm{j}$ that the negative connection tends to be associated with the EOF2 of ASM variability mainly during the developing ENSO phase. 
Ding and Wang (2005) demonstrated that the negative connection is the major component of circumglobal teleconnection pattern (CGT) along the upper-level westerly jet. The CGT wave pattern is mainly driven by the SAM rainfall, while the zonally symmetric pattern of the CGT is generated by the developing ENSO. It has been shown that the CGT wave pattern has weakened after the 1970s (Wang et al. 2012).

\subsection{Decaying ENSO}

The positive SAM-EAM relationship is mainly influenced by a wave propagating over Tropics along the lower-level monsoon westerly (Wang et al. 2001, 2013, Hsu and Lin 2007; Liu et al. 2008; Yun et al. 2008, 2010; Lee et al. 2011a, b, 2013) that preferentially occurs during the decaying phase of the ENSO (Ding et al. 2010; Lee et al. 2011a, b; Wang et al. 2013, 2015; Chen et al. 2016; Ha et al. 2017). The tropical teleconnection is called the western North Pacific-North America (WPNA) pattern, including the WPSH as an important factor bridging the SAM and EAM climate (Wang et al. 2001; Kosaka et al. 2013; Lee et al. 2013a, b).

Note that the EOF1 of ASM variability is accompanied by the decaying El Niño and developing warm SST anomalies in the tropical IO and MC (Fig. 7a-e). The geopotential height fields at 850 -hPa during JJA show a prominent low-level anticyclone over the subtropical WNP and North Pacific, and a dominant low-level cyclone over Japan and Korea. This circulation pattern captures a wave train in the meridional direction from the WNP to the north of Japan and a westward extended North Pacific subtropical high (NPSH), called the WNPSH. This pattern resembles the Pacific-Japan (PJ) pattern previously suggested by Nitta (1987) and Huang and Wu (1989). Ding et al. (2010) reported that persistent IO SST warming plays an important role in modulating the WNPSH and EAM circulation by affecting the formation of anomalous WNPSH. Lau and $\mathrm{Wu}$ (2001) suggested that the strong monsoon-ENSO connection tends to occur with a pronounced 2-year polarity switch in basin-scale SST anomalies, i.e., the transition phases, and that therefore, the monsoon-ENSO relationship needs to be considered in pairs of years with respect to the evolution of the SST. The IO and MC SST warming after the mature phase of the El Niño is a delayed response to remote $\mathrm{El}$ Niño forcing through the atmospheric bridge. These anomalies are located to the west and southwest of the WNPSH. Li et al. (2007) argued that the two subtropical highs over the south IO and WNP play a crucial role in linking the Asian monsoon to the ENSO. The relationship between the EOF1 and monsoon indices in Table 4 indicates that the EOF 1 and associated WNPSH variability play a critical role on the positive SAM-EAM relationship during recent three decades.

\subsection{IODM and Eurasian snow}

It has been suggested that the IODM (Saji et al. 1999) has an impact on global climate, including the regional monsoon variability over the SAM and EAM. Recent studies have shown that the impact of IODM is more on the EAM rather than on the SAM (Kripalani and Kulkarni 1999; Kripalani and Kumar 2004; Kripalani et al. 2005, 2010; Kulkarni et al. 2007), but the IODM in fall season (SON) can be affected by the SAM in summer season (JJA) (Kripalani et al. 2010). Thus, the IODM can act as a bridge on the delayed relationship between the SAM and EAM.

Kripalani et al. (2010) demonstrated that the IODM has a significant delayed impact on the EAM. The peak positive phase of the IODM during September-October-November (SON) can suppress the convective activity over the WNP-EAM region in the following summer. Furthermore, the SON IODM can also induce heavy snow over Eastern Eurasia, north of the Korea-Japan peninsula in the following December-January-February (DJF) and March-April-May (MAM) that leads to the transport of cold and dry air from the northern latitudes to the lower latitudes over East Asia. Thus, the footprints of the delayed effect of the IODM can be carried by the snow distribution over eastern Eurasia. Figure 8 indicates that the IODM has a stronger relation with the subsequent snow distribution over Eurasia than the ENSO whereas the IODM and ENSO act cooperatively to affect summer rainfall variability over the WNPM and EAM region (Kripalani et al. 2010).

Figure 9 shows how the Eurasian snow distribution influences the mid-latitude atmospheric circulation affecting the EAM region with the prevailing Rossby wave train emanating from western Eurasia during MAM and JJA after the extreme snow depth event. During JJA, the anomalous anticyclonic circulation tends to advect cold and dry air from the north toward East Asia leading to suppressed convective activity over the EAM region. Figure 10 summarizes the connection between the SAM in preceding summer, IODM in preceding fall, and EAM in following summer. The delayed impact of the IODM on the EAM summer monsoon variability is possibly carried out not only by the Eurasian snow but also SSTs vis the Indonesian through flow. More details are available in Kripalani et al. (2010).

\subsection{Relative role of tropical SST forcing in numerical experiments}

To demonstrate the relative roles of different tropical thermal states, such as developing and decaying ENSO, a 
(a)

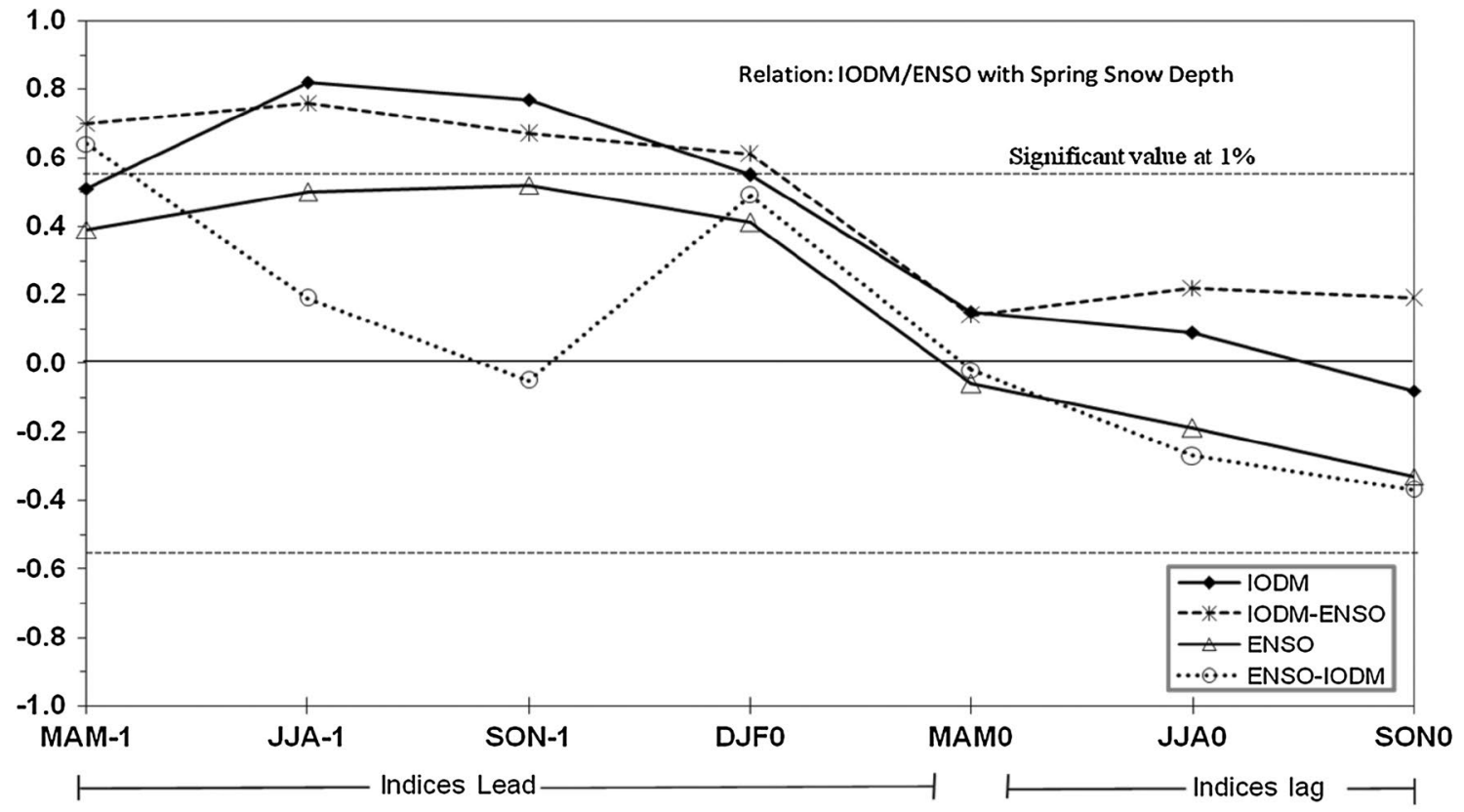

(b)

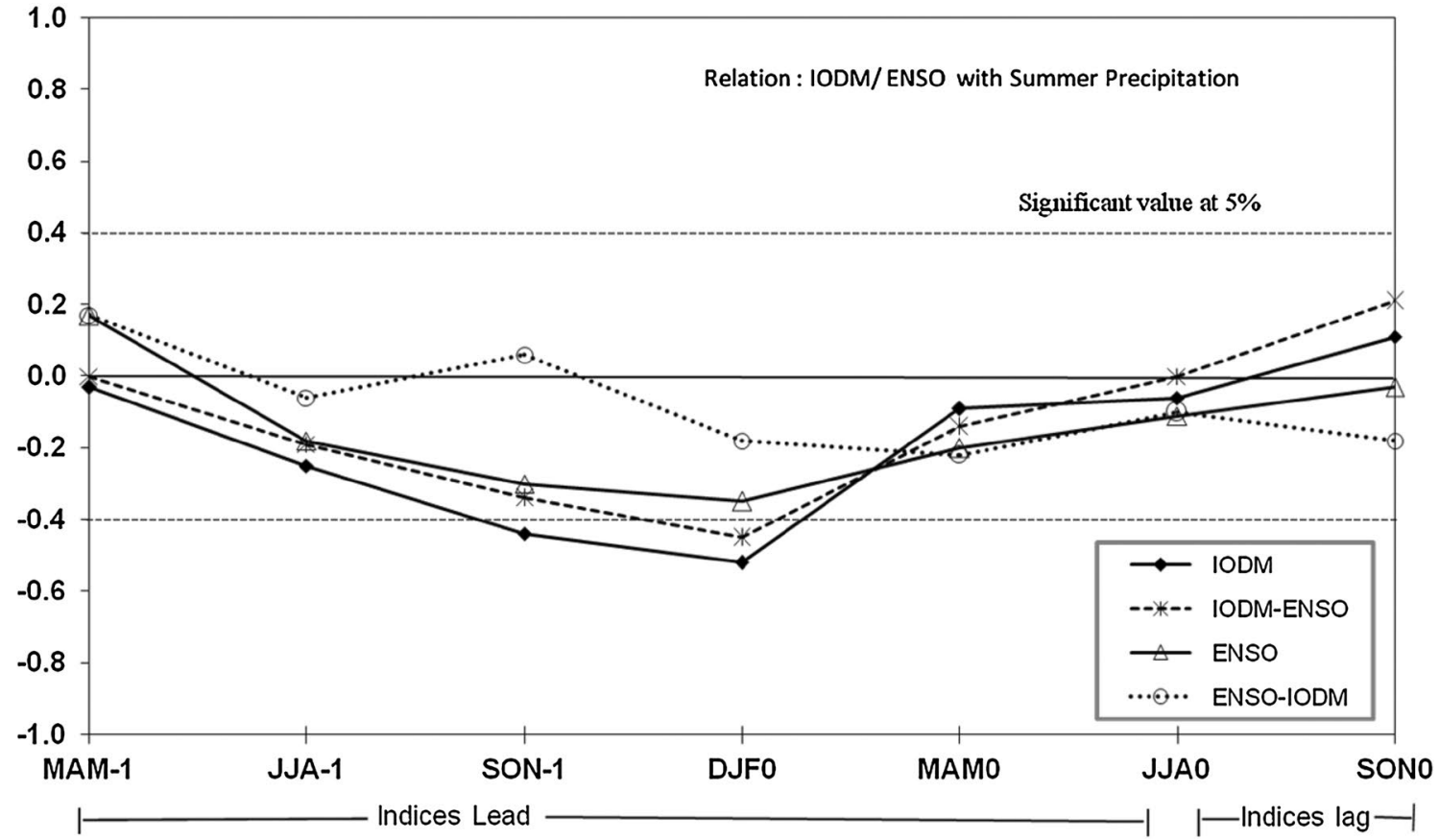

Fig. 8 TCCs for the seasonal IODM and ENSO indices with a MAM snow depth over Eastern Eurasia-north of the Korea-Japan peninsula (EENKJ: $45^{\circ}-60^{\circ} \mathrm{N}, 120^{\circ}-140^{\circ} \mathrm{E}$ ) region and $\mathbf{b}$ the area-mean JJA precipitation over the East Asia-West North Pacific (EAWNP: $15^{\circ}-$ $\left.25^{\circ} \mathrm{N}, 120^{\circ}-140^{\circ} \mathrm{E}\right)$ region. IODM-ENSO (ENSO-IODM) indicates the partial correlation with IODM (ENSO) after removing the effect of ENSO (IODM). Snow depth data are from the National Snow and Ice Data Center, Colorado, USA and precipitation data are from CMAP for 1979-2003. This figure is adapted from Kripalani et al. (2010) 
Fig. 9 Composite differences of 500-hPa geopotential heights (unit: $\mathrm{m}$ ) for the extreme snow depth events (heavy minus light snow over EENKJ region) in MAM (upper panel) and JJA (lower panel). Solid (dashed) contours indicate positive (negative) anomalies. Grey shading indicates the areas of significance at the $95 \%$ confidence level. The geopotential height data are from NCEP-NCAR reanalysis for 1979-2003. This figure is adapted from Kripalani et al. (2010)
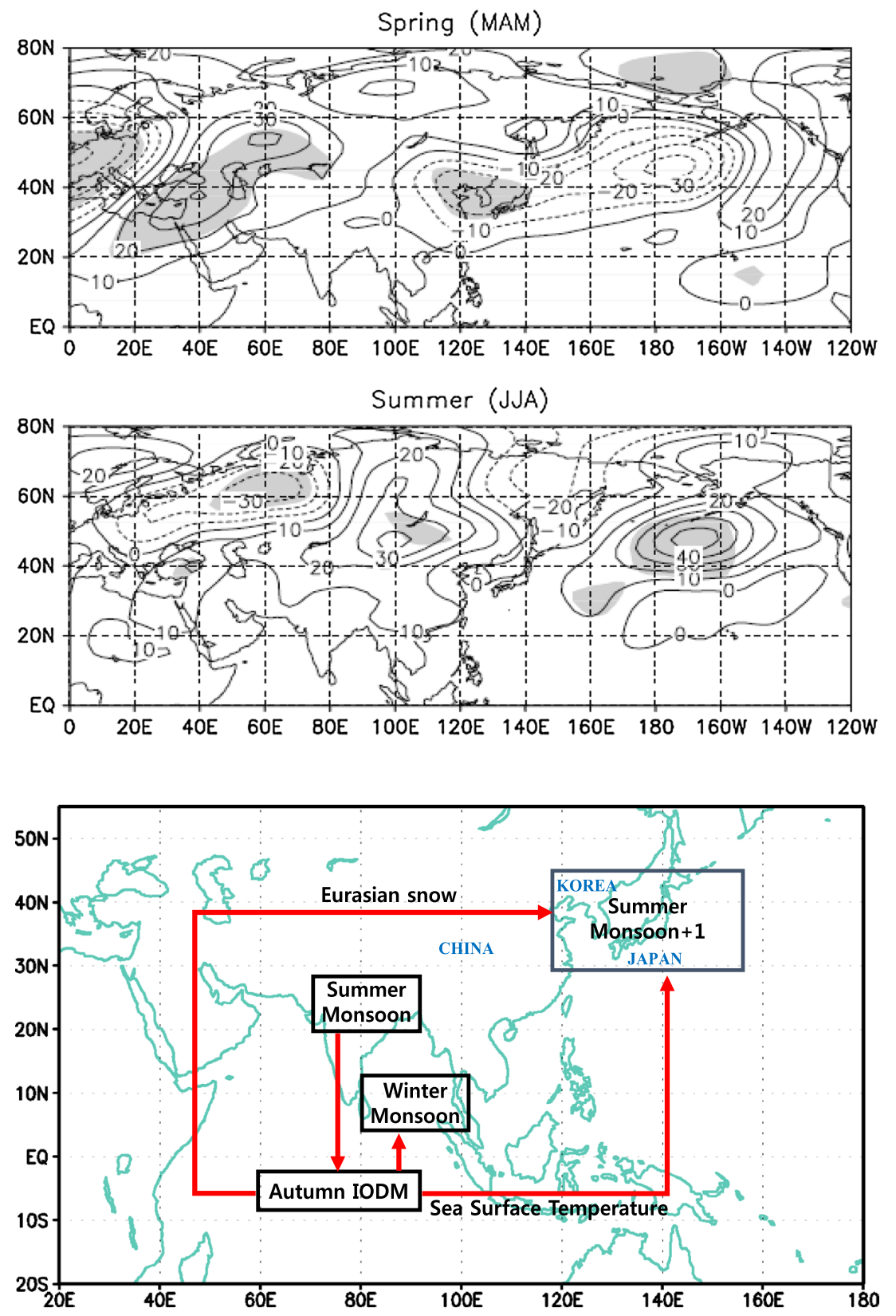

Fig. 10 Schematic representation illustrating the impact of JJA(0) SAM on SON(0) IOD and that of $\operatorname{SON}(0)$ IOD on $\mathrm{OND}(0)$ precipitation over south peninsular India; impact of $\operatorname{SON}(0)$ IOD on $\operatorname{EAM}(+1)$ through the DJFMAM $(+1)$ Eurasian snow and Indonesian through-flow SSTs series of numerical model experiments was performed. This subsection summarizes the relative role of tropical SST forcing on the SAM-EAM relationship. The IO, WP, and EP SST forcings were set to twice the combined PC1 and $\mathrm{PC} 2$ regressed SST anomalies. Table 2 provides detail information on model experiments and Fig. 2 shows SST distribution prescribed at each AGCM experiment as discussed in Sect. 2.2. It is important to mention that AGCM experiments have an intrinsic limitation on explaining summer monsoon variability in which air-sea interaction plays an essential role (e.g., Wang et al. 2004; Wu and Kirtman 2007). However, it can at least explain forced response to different SST among monsoon variability.
Analysis of model experiments suggest that the IO SST warming anomalies affect active convection over the Bay of Bengal, MC, and EAM region inducing enhanced precipitation over these regions (Fig. 11a). On the contrary, suppressed convection appears over the Bay of Bengal and WNP, induced by the strong WNPSH affected by the remote forcing of the El Niño to La Niña transition (Fig. 11b). Lu and Dong (2001) showed that the suppressed convection over the warm pool is related to the westward extension of the WNPSH. Consequently, remote thermal forcing contributes to the development of the WNPSH, which helps to moisten the EAM region, and IO SST warming provides a favorable condition for an active SAM 
Fig. 11 Difference in precipitation (contour, unit: $\mathrm{mm} \mathrm{day}^{-1}$ ) and OLR (shading, unit: $\mathrm{Wm}^{-2}$ ) anomaly between CTRL and each EXP run: a IOwm, b EPwc, c IOwm + EPwc, d WPcl, e EPwm, and f $\mathrm{WPcl}+\mathrm{EPwm}$ (a) $10 \mathrm{wm}$

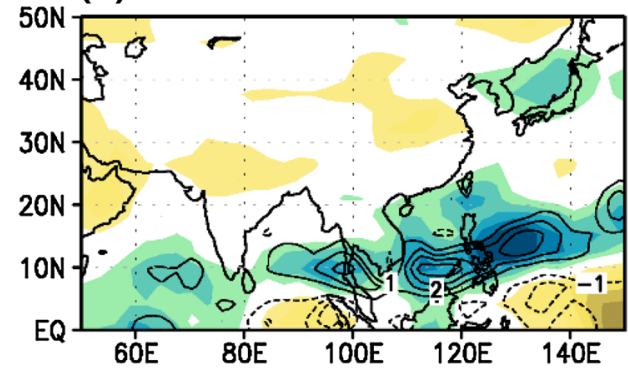

(b) EPwc

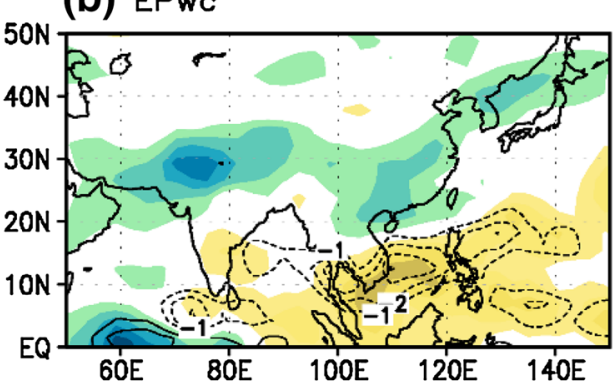

(c) $10 w m+E P w c$

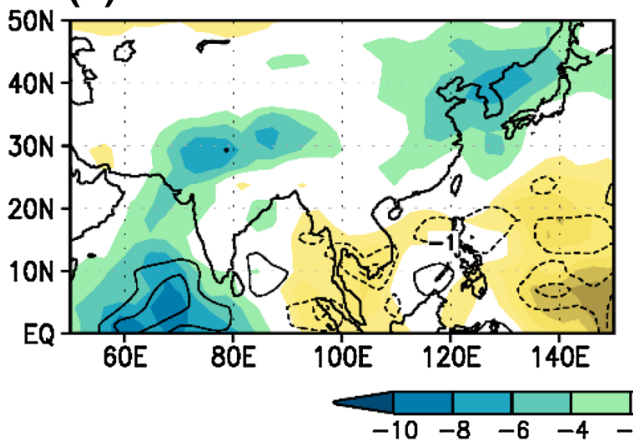

(d) WPcl

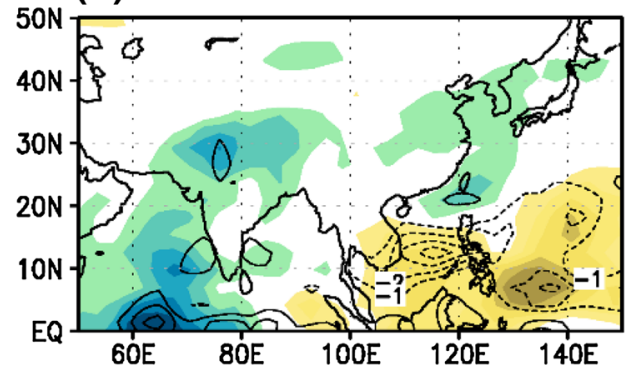

(e) EPwm

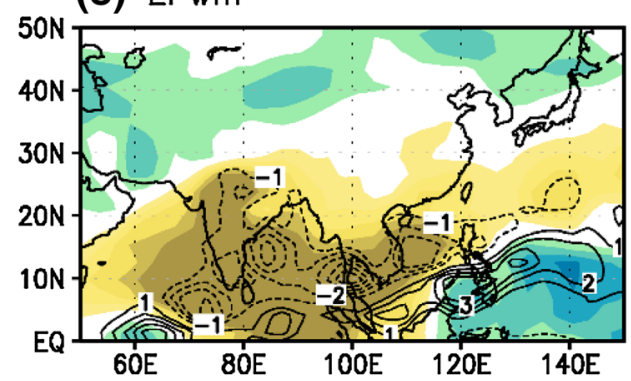

(f) WPcl+EPwm

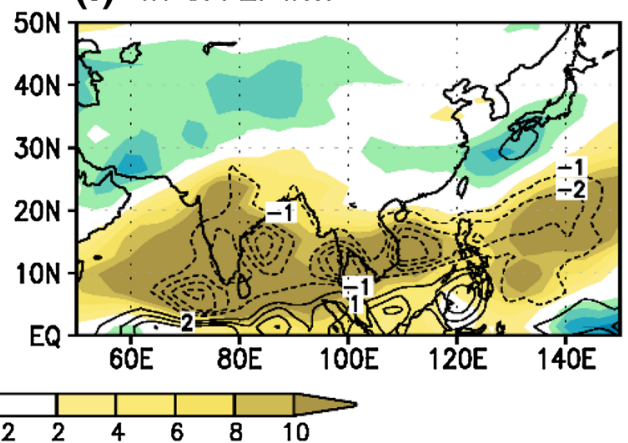

(Fig. 11c). It is noted that this mechanism tends to amplify both the SAM and EAM precipitation simultaneously in the boreal summer. The ENSO efficiently excites the PJ teleconnection pattern associated with the WNPSH by inducing IO SST anomalies as an initial perturbation (Kosaka et al. 2013; Chowdary et al. 2014).

For the case of negative inter-correlation, either the WP SST cooling anomalies or the EP SST warming anomalies play a role. On one hand, the WP SST cooling anomalies generate a zonal dipole pattern over the IO and MC and a meridional dipole pattern over the WP and EAM region (Fig. 11d). This system is tightly coupled with both the Hadley and Walker circulations, providing favorable condition for an enhancement of WNPSH and increased rainfall over the EAM. On the other hand, the EP SST warming anomalies trigger a strong suppressed convection over the IO and Bay of Bengal and enhanced convection over the equatorial WP that shift the WNPSH northward (Fig. 11e). During El Nino developing summer, the WP cooling and EP warming coexist. They together can provide a favorable condition for the negative SAM-EAM relationship characterized by enhanced convection over the EAM but suppressed convection over the SAM (Fig. 11f). Therefore, the combined effect of the ENSO evolution and the local thermal forcing plays important roles in modulating the WNPSH and exerting the negative SAM-EAM relationship.

\section{Discussion and summary}

\subsection{Recent intensification}

Intensification of the negative SAM-EAM connection on interannual timescale and the SAM-EAM contrast on interdecadal timescale has been found in several previous studies (Kim et al. 2002; Kripalani et al. 2002; Yun et al. 2014). Yun et al. (2014) demonstrated the significant recent intensification in the contrast. Figure 12 illustrates the 21-year running mean of the standardized summer monsoon rainfall 


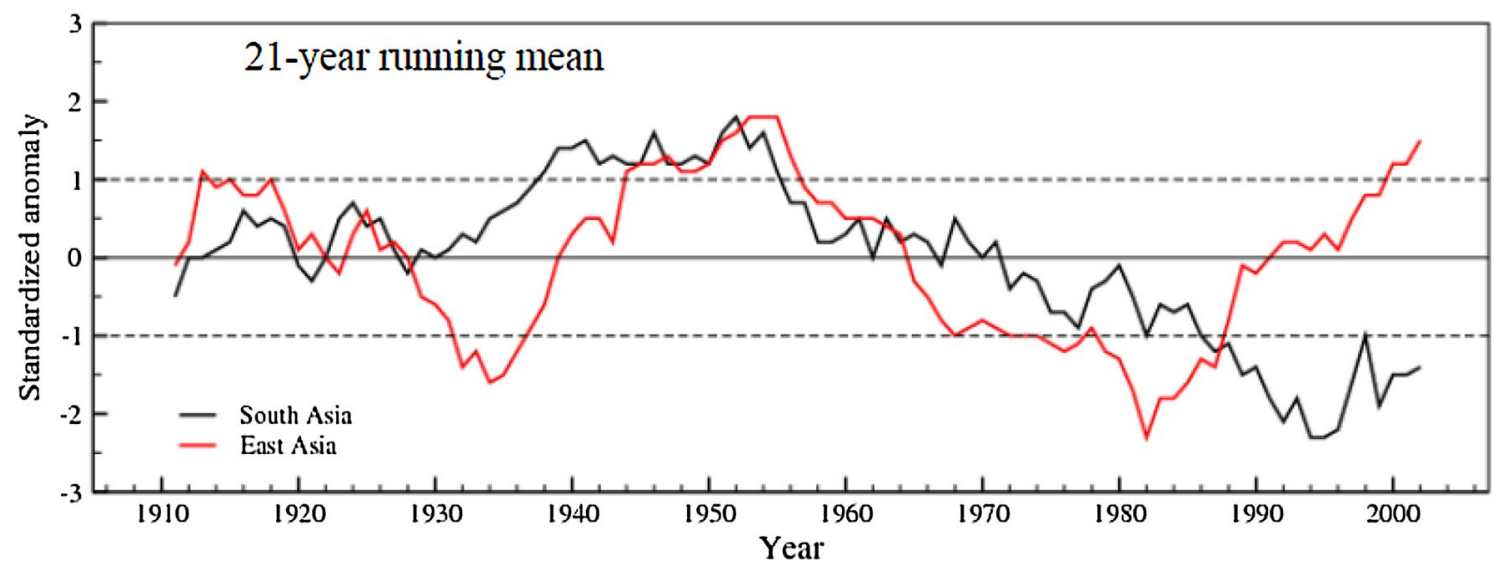

Fig. 12 21-year running mean of standardized anomaly of SAM and EAM rainfall over land region only obtained from CRU data

Fig. 13 a Time series of the normalized indices of Niño3.4, Pacific Decadal Oscillation (PDO), SST zonal gradient between the western and eastern Pacific (WP-EP_zg), SST zonal gradient between the western Pacific and Indian Ocean (WP-IO_zg), and SAMEAM in June and July during 1979-2013. b Same as a, but for 7-year running mean time series. SST data are from the Extended Reconstructed Sea Surface Temperature (ERSST).

This figure is adapted from Yun et al. (2014) (a) June-July Climate indices

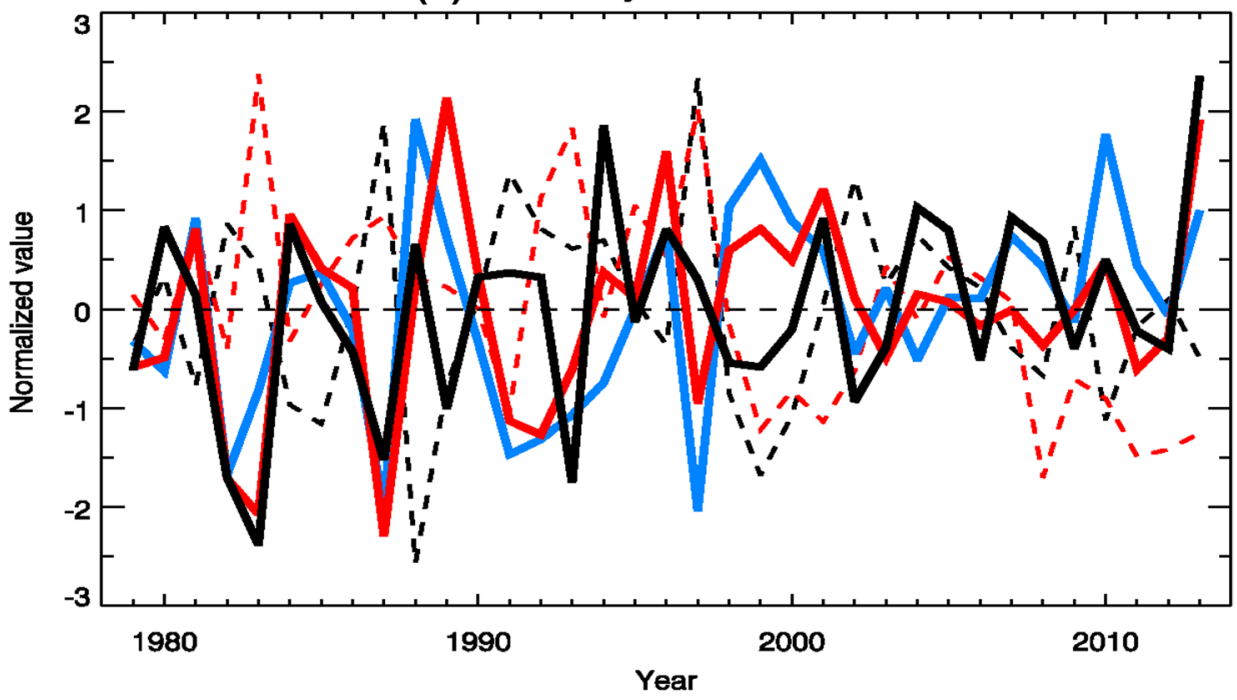

(b) June-July Climate indices with 7-yr running mean

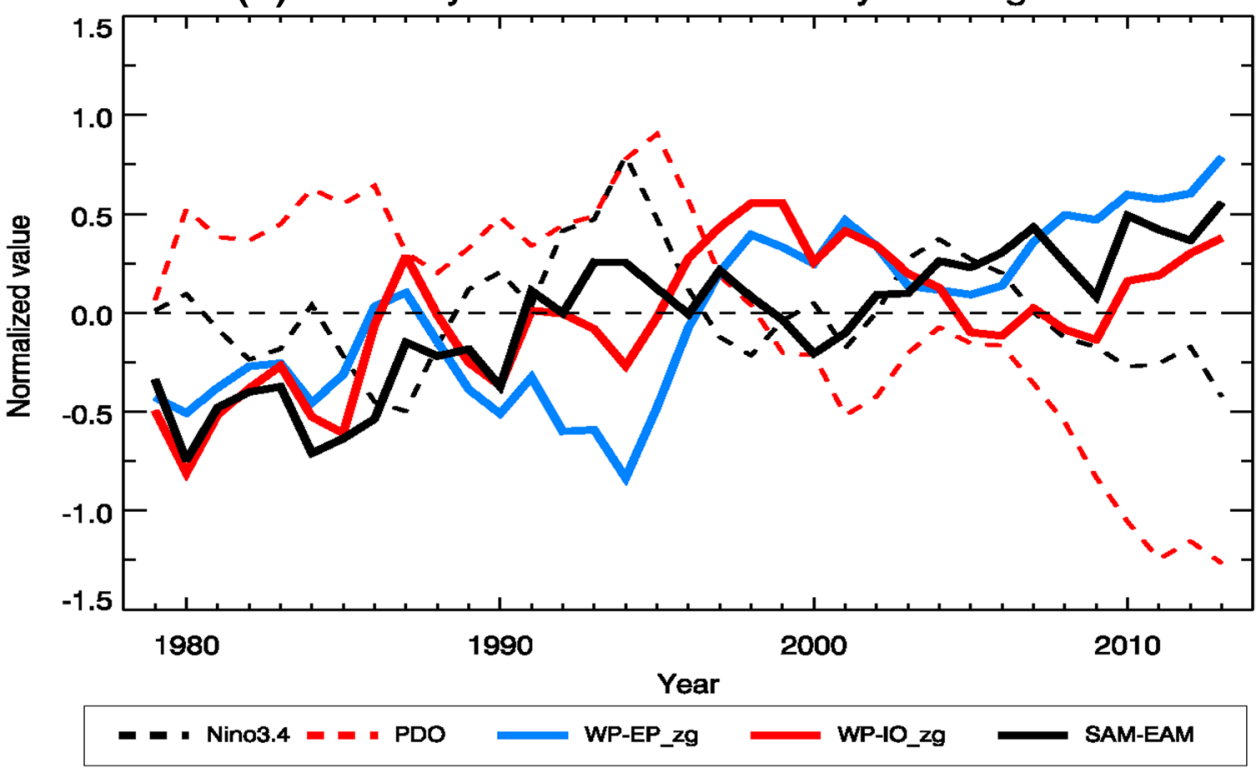


over South and East Asia for the entire twentieth century using CRU data. The variations appear to be in a phase up to 1980; thereafter, an increase in summer precipitation is indicated over East Asia, while South Asia continues to reel under a declining trend. Incidentally, this diversion of precipitation over South and East Asia appears to commence during the climate shift period around the mid-1970s. To determine whether the amplification of the negative relationship is related to the recent global warming requires a separate investigation. At the interannual and interdecadal timescales, the monsoon contrast is significantly correlated with the variabilities of the zonal SST gradient along the IO, WP, and EP, and is attributed to the recent negative Pacific decadal oscillation (PDO) and mega-La Niña (Fig. 13) (Yun et al. 2014). However, possible impacts of other climate factors (e.g., IODM) on the increasing monsoon contrast cannot be ruled out and it remains an open question.

\subsection{Extreme cases}

There are several extreme cases showing a negative connection between the SAM and EAM such as in 2009, 2010, and 2013. During the summer of 2009, India suffered one of its worst droughts with a seasonal deficit of $23 \%$
(Ratnam et al. 2010), but the EAM region experienced cool and wet conditions. Ha et al. (2012) pointed out that the negative phase of the CGT associated with the considerable deficit of the ISM rainfall excited a strong cold wave train along $35^{\circ} \mathrm{N}-40^{\circ} \mathrm{N}$, resulting in cold and wet extremes over the EAM region in 2009 (Fig. 14).

On the contrary, extreme monsoon rains and flooding over Pakistan in 2010 and 2013 were associated with hot and dry conditions over the EAM region and Russia; this is mostly attributable to the excitation of quasi-stationary Rossby waves in 2010 (Barriopedro et al. 2011; Lau and Kim 2012; Webster et al. 2012; Watanabe et al. 2013) and to the modulation in the local Hadley circulation due to a shift in the mid-latitude jet in 2013 (Yun et al. 2014; Imada et al. 2014). Studies on such extreme cases will further help to better understand the SAM-EAM connection.

\subsection{Future changes}

It is of particular importance to investigate whether the recent intensification of the SAM-EAM contrast will continue under anthropogenic global warming in the future. Experiments in the CMIP5 indicate that the mean and variability of the monsoon precipitation in the SAM and EAM region will significantly increase due to the increase in the
Fig. 14 Spatial pattern of a $2 \mathrm{~m}$ air temperature (TMP, shading, unit: ${ }^{\circ} \mathrm{C}$ ) and precipitation (PRCP, brown and green contour, unit: $\mathrm{mm} \mathrm{day}^{-1}$ ) anomaly and b 200-hPa geopotential height (Z200, shading, unit: $\mathrm{m}$ ) and $850-\mathrm{hPa}$ wind (vector, unit: $\mathrm{ms}^{-1}$ ) anomaly during JuneJuly 2009. Three box regions indicate northern Central Asia, northern East Asia, and central North America. In b 20 and $30 \mathrm{~ms}^{-1}$ of 200 -hPa zonal wind are superimposed (red contour). The data are obtained from CMAP for PRCP, NCEP reanalysis II for TMP, Z200, and 200-hPa and 850-hPa wind from 1979 to 2010. This figure is adapted from Ha et al. (2012) (a) $2 \mathrm{~m} T \mathrm{TMP}$ (shading) \& $\mathrm{PRCP}$ (contour)

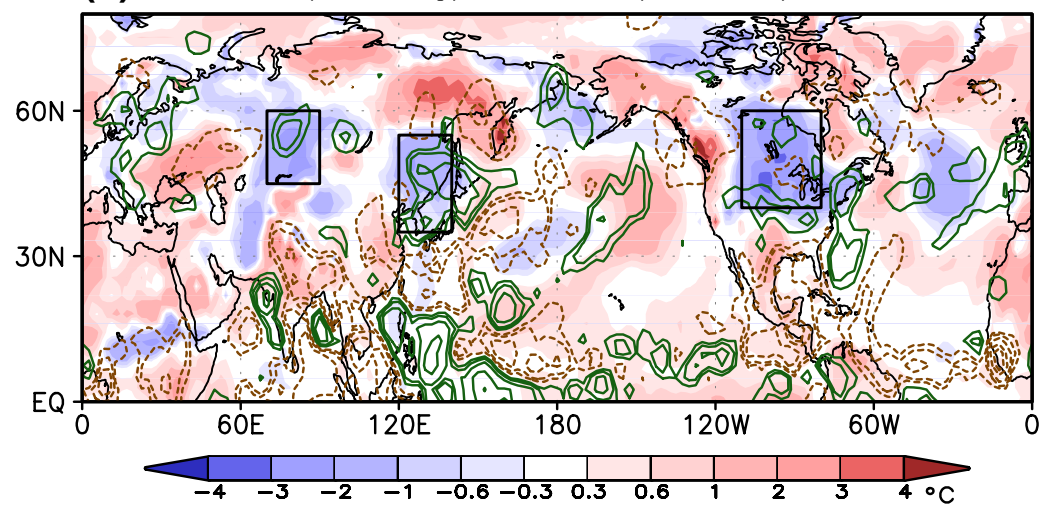

(b) $\mathrm{Z} 200$ (shading) \& $850-\mathrm{hPa}$ Wind(vector)

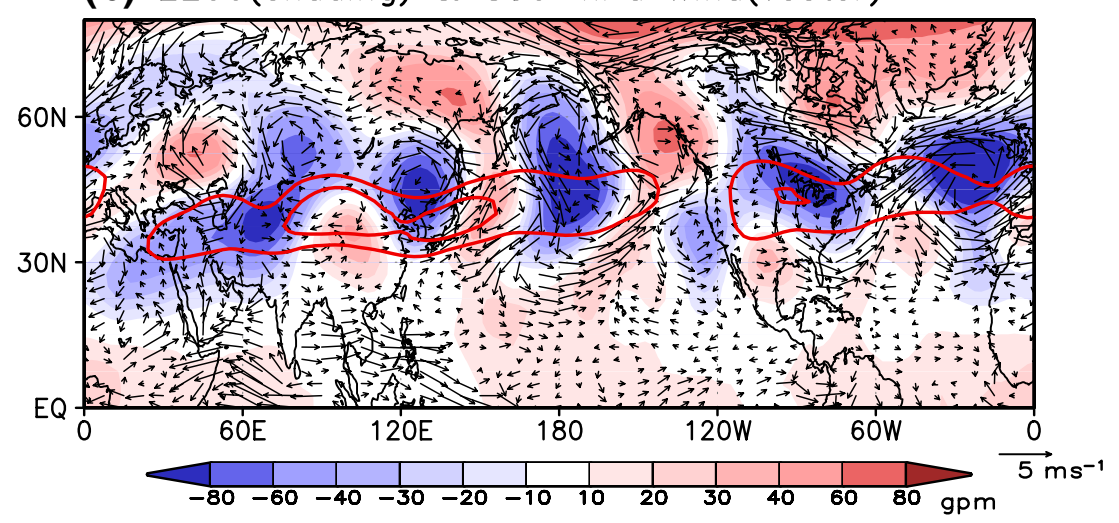


Fig. 15 Scatter diagram showing the projected changes in precipitation and circulation intensities in the twenty-first century obtained from CMIP5 RCP 4.5 experiments as functions of global mean $2 \mathrm{~m}$ air temperature over the ASM, Australian summer monsoon region (AusSM: $5^{\circ}-20^{\circ} \mathrm{S}, 110^{\circ}$ $150^{\circ} \mathrm{E}$ ), and sub-monsoon areas. 5-year average was applied. The ISM (EASM) is obtained using the area of $12.5^{\circ}-22.5^{\circ} \mathrm{N}$, $70^{\circ}-105^{\circ} \mathrm{E}\left(22.5^{\circ}-42.5^{\circ} \mathrm{N}\right.$, $\left.110^{\circ}-140^{\circ} \mathrm{E}\right)$. The percentage rate in the parenthesis indicates the change with respect to the present day (1980-2005) given one degree warming and the values of the trend exceeding $95 \%$ confidence level are marked by asterisk. This figure is adapted from Wang et al. (2014)
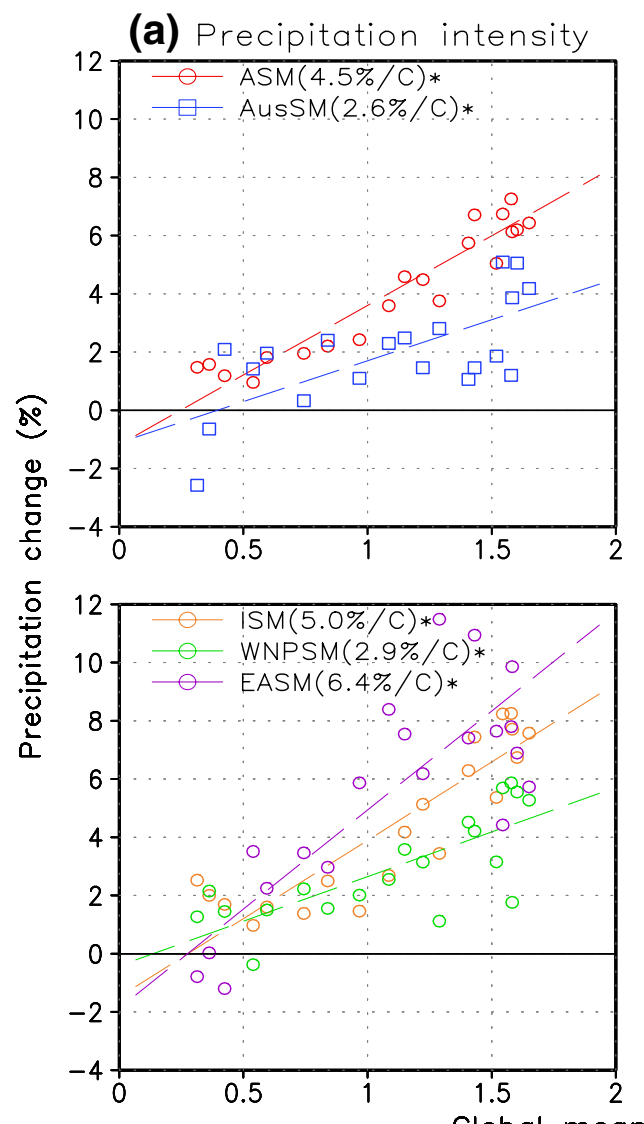

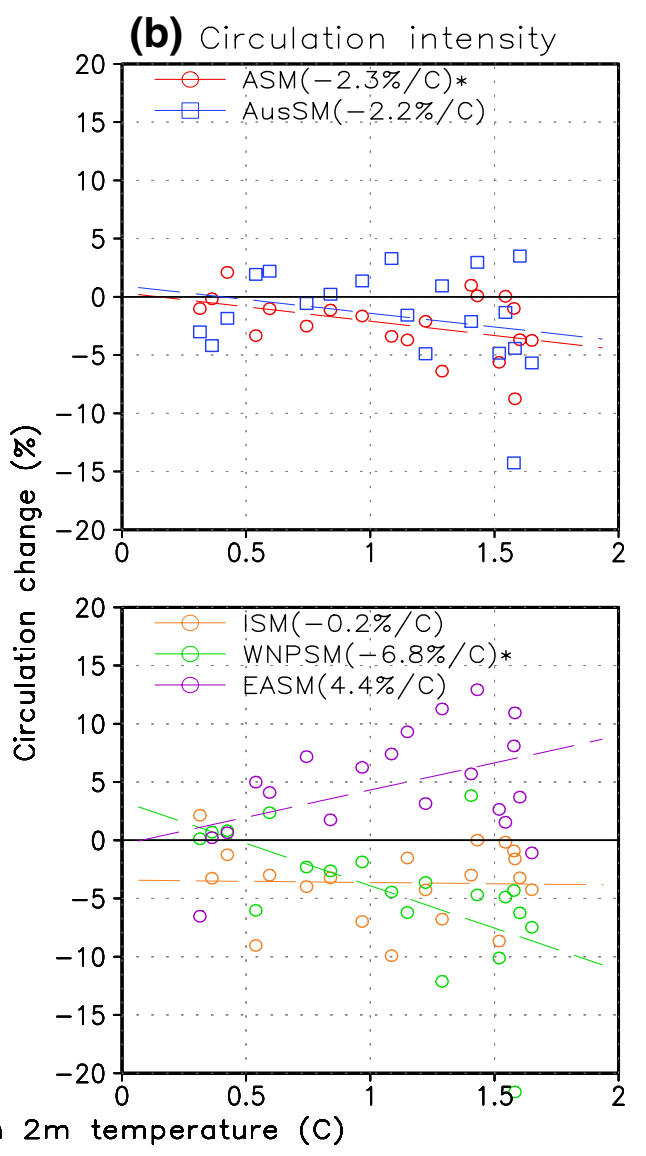

amount of greenhouse gases (Lee and Wang 2014; Wang et al. 2014; Lee et al. 2014a, b). However, the precipitation increase is expected to be larger in the EAM region because monsoon circulation will be enhanced in the EAM region but decrease in the SAM region (Wang et al. 2014), as shown in Fig. 15.

By analyzing the CMIP5 experiments, this study further reveals that the negative SAM-EAM relationship will be strengthened with significant interdecadal modulation due to the increase in the amount of greenhouse gases. Figure 16 illustrates the spatial patterns of the correlation coefficients of precipitation at each grid point with the time series of the SAMP index. The spatial pattern shown on the upper left panel is based on the observations (GPCP data), while the pattern on the upper right is based on an ensemble of about 9 selected CMIP5 models (Preethi et al. 2017). In observation, SAMP has a negative relationship with rainfall variability over many part of EAM. However, there is a positive relationship as well over some part of southern China, north of Korea, and Japan that may weakened the SAM-EAM relationship. The CMIP5 models are able to capture the negative relationship between the SAM and EAM but tend to underestimate the negative (positive) correlation with WNPSM (Maritime Continent) rainfall. The bottom panel shows the 11-year running correlation coefficients between the SAMP and EAMP based on simulations of the 19th and the twentieth century and projections for the twenty-first century by an ensemble of 30 CMIP5 models. While the correlation pattern exhibits inter-decadal fluctuations, a noteworthy feature is the intensification of the negative interannual relationship during the twenty-first century implying that a deficient (excess) summer monsoon over South Asia may be accompanied by an excess (deficient) monsoon over East Asia in the future.

\section{Conclusions}

This review paper provides a comprehensive view on the inter-connection between the SAM and EAM. Significant emphasis has been placed on the underlying mechanisms modulating the diversity of the SAM-EAM relationship. A variety of statistical and empirical analyses reveal that the primary inter-connection between the SAM and EAM is caused by different external forcings, such as the ENSO, IODM, Eurasian snow, and tropical-extratropical teleconnections. Decaying El Niño and developing IO SST warming anomalies are connected with the WPNA teleconnection pattern, corresponding to the positive inter-correlation between the two monsoon 

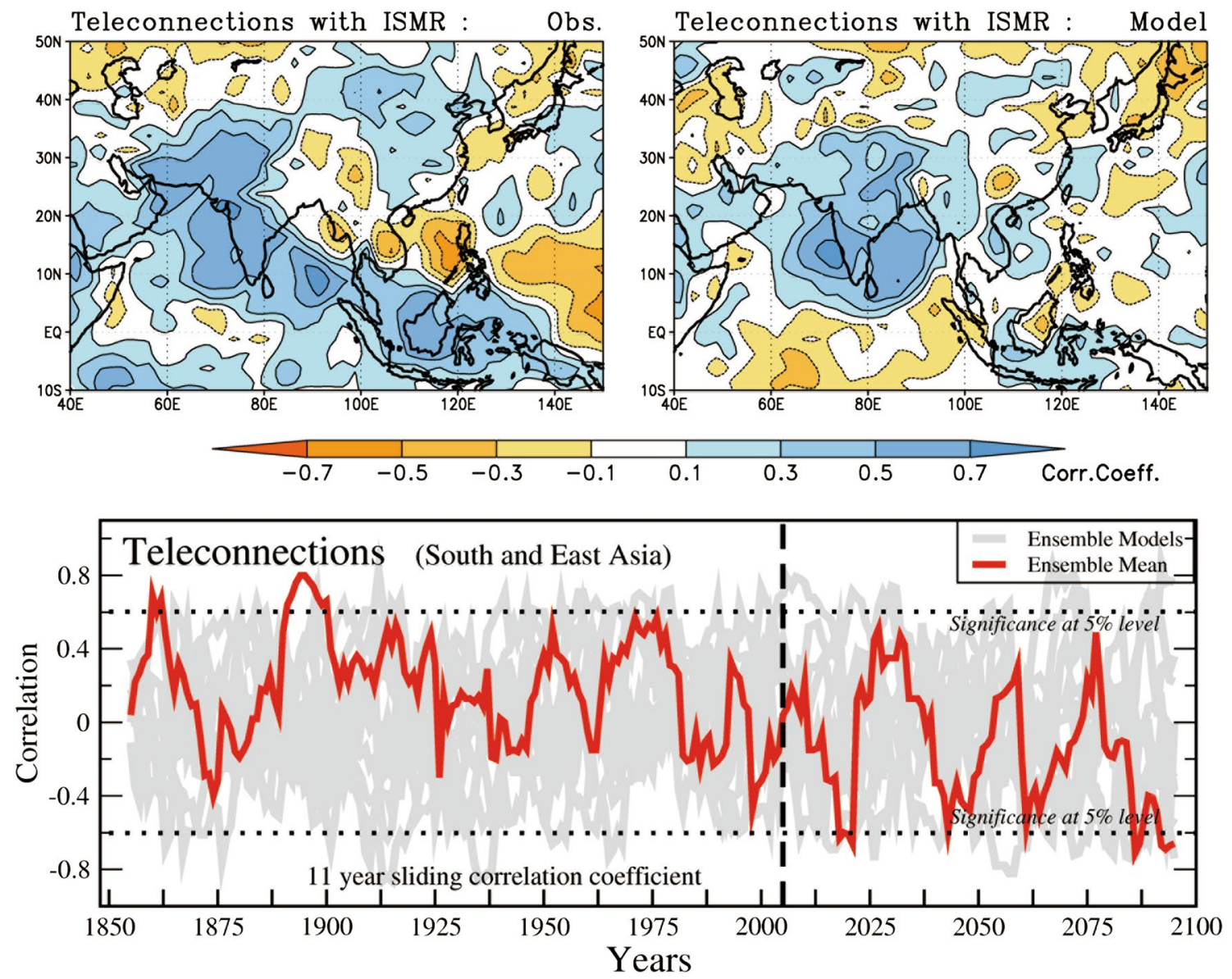

Fig. 16 Spatial patterns of the TCCs between rainfall over Asia and SAMP based on observations (upper left) using GPCP and on the CMIP5 models (upper right) during boreal summer. The ISMR in the

systems. Meanwhile, developing El Niño and developing WP cooling SST anomalies are associated with the CGT pattern and negative inter-connection. The negative interconnection is also contributed to by the delayed impact of the IODM caused by the modulating Eurasian snow cover. The observation and model experiment results support the hypothesis that the differences in the phase relationship between the SAM and EAM are driven by different tropical SST forcings over the IO, WP, and EP regions. Thus, the inter-correlation between the EAM and SAM might be controlled by the thermal condition over the tropics. Because of the competitive mechanisms, it is very difficult to predict the linkage between the SAM and EAM at interannual and interdecadal timescales. The complex mechanisms have important implications for seasonal climate prediction of summer monsoon precipitation that remains very difficult (Wang et al. 2008, 2009; Lee et al. 2010; Kosaka et al. 2012; Chowdary et al. 2014 upper panel indicates SAMP. Bottom panel shows the 11-year running TCC between SAMP and EAMP obtained from CMIP5 models from 1850 to 2100

and many others). Although the CMIP5 models project an intensification of the negative SAM-EAM relationship in the future, the question of whether and to what extent the inter-connection would have changed under natural climate changes as opposed to anthropogenic climate changes remains a significant unsolved scientific issue.

Acknowledgements This work was supported by the Global Research Laboratory (GRL) grant (MEST 2011-0021927) and the research grant (No. 2015R1C1A2A01053980) both funded by the National Research Foundation of Korea (NRF) from the Korea government (MSIP).

Open Access This article is distributed under the terms of the Creative Commons Attribution 4.0 International License (http:// creativecommons.org/licenses/by/4.0/), which permits unrestricted use, distribution, and reproduction in any medium, provided you give appropriate credit to the original author(s) and the source, provide a link to the Creative Commons license, and indicate if changes were made. 


\section{References}

An ZS, Porter SC, Kutzbach JE, Wu XH, Wang SM, Liu XD, Li XQ, Zhou WJ (2000) Asynchronous Holocene optimum of the East Asian monsoon. Quat Sci Rev 19:743-762

An Z, Wu G, Li J, Sun Y, Liu Y, Zhou W, Cai Y, Duan A, Li L, Mao J, Cheng H, Shi Z, Tan L, Yan H, Ao H, Chang H, Feng J (2014) Global monsoon dynamics and climate change. Annu Rev Earth Planet Sci. doi:10.1146/annurev-earth-060313-054623 (in press)

Bandgar AB, Chowdary JS, Gnanaseelan C (2014) Indian summer monsoon rainfall predictability and variability associated with northwest Pacific circulation in a suit of coupled model hindcasts. Theor Appl Climatol 118:69-79

Barriopedro D, Fischer EM, Luterbacher J, Trigo RM, Garcia-Herrera R (2011) The hot summer of 2010: redrawing the temperature record map of Europe. Science 332:220-224

Bollasina M, Nigam S (2008) Absorbing aerosols and summer monsoon evolution over South Asia: an observational portrayal. J Clim 21:3221-3239

Bollasina MA, Ming Y, Ramaswamy V (2011) Anthropogenic aerosols and the weakening of the South Asian summer monsoon. Science 28:502-505. doi:10.1126/science.1204994

Cao J, Hu J, Tao Y (2012) An index for the interface between the Indian summer monsoon and the East Asian summer monsoon. J Geophys Res 117:D18108. doi:10.1029/2012-JD17841

Chang CP, Wang B, Lau NC (eds) (2005) The global monsoon system: research and forecast report of the International Committee of the Third International Workshop on Monsoons. Secretariat of the World Meteorological Organization

Chen FH, Cheng B, Zhao Y, Zhu Y, Madsen DB (2006) Holocene environmental change inferred from a high-resolution pollen record, Lake Zhuyeze, arid China. Holocene 16:675-684

Chen J, Wen Z, Wu R, Lin X, Wang J (2016) Relative importance of tropical SST anomalies in maintain the Western North Pacific anomalous anticyclone during El Nino to La Nina transition years. Clim Dyn 46:1027-1041

Chen F, Yu Z, Yang M, Ito E, Wang S, Madsen DB, Huang X, Zhao Y, Sato T, Birks HJB, Boomer I, Chen J, An C, Wünnemann B (2008) Holocene moisture evolution in arid central Asia and its out-of-phase relationship with Asian monsoon history. Quat Sci Rev 27(3-4):351-364

Choi KS, Moon JY, Kim DW, Byun HR, Kripalani RH (2010) The significant increase of summer rainfall in Korea from 1998. Theor Appl Climatol 102:275-286

Chowdary JS, Gnanaseelan C, Chakravorty S (2013) Impact of northwest Pacific anticyclone on the Indian summer monsoon region. Theor Appl Climatol 113:329-336

Chowdary JS, Attada R, Lee JY, Kosaka Y, Ha KJ, Luo JJ, Gnanaseelan C, Parekh A, Lee DY (2014) Seasonal prediction of distinct climate anomalies in the summer 2010 over the tropical Indian Ocean and South Asia. J Meteor Soc Jpn 92(1):1-16

Chu J-E, Wang B, Lee J-Y, Ha K-J (2017) Boreal summer intraseasonal phases identified by nonlinear multivariate empirical orthogonal function? based self-organizing map (ESOM) analysis. J Clim 30(10):3513-3528

Clift PD, Plumb RA (2008) The Asian monsoon: causes, history, and effects. Cambridge University Press, Cambridge

Dai XG, Chou JF, Wu GX (2002) The tele-connection relationship between Indian summer monsoon and East Asian summer circulation. Acta Meteorol Sin 60:544-552 (in Chinese)

Dee DP, Uppala SM, Simmons AJ, Berrisford P, Poli P, Kobayashi S, Andrae U, Balmaseda MA, Balsamo G, Bauer P, Bechtold P, Beljaars ACM, van de Berg L, Bidlot J, Bormann N, Delsol C, Dragani R, Fuentes M, Geer AJ, Haimberger L, Healy SB,
Hersbach H, Hólm EV, Isaksen L, Kållberg P, Köhler M, Matricardi M, McNally AP, Monge-Sanz BM, Morcrette JJ, Park BK, Peubey C, de Rosnay P, Tavolato C, Thépaut JN, Vitart F (2011) The ERA-Interim reanalysis: configuration and performance of the data assimilation system. Q J R Meteorol Soc 137:553-597

Ding Q, Wang B (2005) Circumpolar teleconnection in the Northern Hemisphere summer. J Clim 5:541-560

Ding Q, Wang B (2007) Intraseasonal interaction between the Eurasian wave train and the Indian summer monsoon. J Clim 20:3751-3767

Ding R, Ha KJ, Li J (2010) Interdecadal shift in the relationship between the East Asian summer monsoon and the tropical Indian Ocean. Clim Dyn 34:1059-1071. doi:10.1007/ s00382-009-0555-2

Ding Q, Wang B, Wallace JM, Branstator G (2011) Tropical-extratropical teleconnections in boreal summer: observed interannual variability. J Clim 24:1878-1896

Flohn H (1958) Large-scale aspects of the summer monsoon in South and East Asia. J Meteorol Soc Jpn 36:180-186

Flohn H (1960) Recent investigation on the mechanism of the summer monsoon of southern and eastern Asia. In: Basu S, Ramanathan KR, Pisharoty PR, Bose UK (eds) Monsoons of the World. India Meteorological Department, Delhi, pp 75-88

Gao QY (1992) Tele-connection between the floods/droughts in North China and Indian summer monsoon rainfall. Acta Meteorol Sin 47:394-402 (in Chinese)

Greatbatch RJ, Sun X, Yang XQ (2013) Impact of the variability in the Indian summer monsoon on the East Asian summer monsoon. Atmos Sci Lett 14:14-19

Guo Q, Wang J (1988) A comparison of the summer precipitation in India with that in China. J Trop Meteorol 4:53-60 (Chinease)

Ha KJ, Park SK, Kim KY (2005) On interannual characteristics of climate prediction center merged analysis precipitation over the Korean peninsula during the summer monsoon season. Int J Climatol 25:99-116

Ha KJ, Chu JE, Lee JY, Wang B, Hameed SN, Watanabe M (2012a) What caused the cool summer over northern Central Asia, East Asia, and central North America during 2009? Environ Res Lett 7(4):044015

Ha KJ, Heo KY, Lee SS, Yun KS, Jhun JG (2012b) Variability in the East Asian monsoon: a review. Meteorol Appl 19(2):200-215

Ha K-J, Chu J-E, Lee J-Y, Yun K-S (2017) Interbasin coupling between the tropical Indian and Pacific Ocean on interannual timescale: observation and CMIP5 reproduction. Clim Dyn 48(1-2):459-475

Harris I, Jones PD, Osborn TJ, Lister DH (2014) Updated high-resolution grids of monthly climatic observations - the CRU TS3.10 Dataset. Int J Climatol 34:623-642. doi:10.1002/joc.3711

He J, Ju J, Wen Z, Lu J, Jin Q (2007) A review of recent advances in research on Asian monsoon in China. Adv Atmos Sci 24:792-992

Hong YT, Hong B, Lin QH, Shibata Y, Horita M, Zhu YX, Leng XT, Wang Y, Wang H, Yi L (2005) Inverse phase oscillations between the East Asian and Indian Ocean summer monsoons during the last 12000 years and paleo-El Niño. Earth Planet Sci Lett 231:337-364

Hsu HH, Lin SS (2007) Asymmetry of the tripole rainfall pattern during the East Asian summer. J Clim 20:4443-4458

Hsu HH, Zhou T, Matsumoto J (2014) East Asian, Indochina and Western North Pacific summer monsoon-an update. Asia Pac J Atmos Sci 50:46-68

Hu ZZ, Nitta T (1996) Wavelet analysis of summer rainfall over north China and India and SOI using 1891-1992 data. J Meteorol Soc Jpn 74:833-844 
Hu ZZ, Wu R, Kinter JL III, Yang S (2005) Connection of summer rainfall variations in South and East Asia: Role of El NiñoSouthern Oscillation. Int J Climatol 25:1279-1289

Huang RH, Wu YF (1989) The influence of ENSO on the summer climate change in China and its mechanism. Adv Atmos Sci 6:21-32

Huffman GJ, Adler RF, Morrissey M, Bolvin D, Curtis S, Joyce R, McGavock B, Susskind J (2001) Global precipitation at onedegree daily resolution from multi-satellite observations. J Hydrometeorol 2:36-50

Imada $\mathrm{Y}$ et al (2014) The contribution of anthropogenic forcing to the Japanese heat waves of 2013, in "Explaining extreme events of 2014 from a climate perspective". Bull Am Meteorol Soc 95:548-551

Jhun JG, Moon BK (1997) Restorations and analyses of rainfall amount observed by Chukwookee (in Korean). J Korean Meteorol Soc 33:691-707

Jin ZH, Chen LX (1982) On the medium-range oscillation of the East Asian monsoon circulation system and its relation with the Indian monsoon system. The National Symposium Collections on the Tropical summer monsoon. People's Press Yunnan Province Kunming China, pp 204-215 (in Chinese)

Kang IS, Ho CH, Lim YK, Lau KM (1999) Principal modes of climatological seasonal and intraseasonal variations of the Asian summer monsoon. Mon Weather Rev 127:322-340

Kim BJ, Moon SE, Lu R, Kripalani RH (2002) Teleconnections: summer monsoon over Korea and India. Adv Atmos Sci 19:665-676

Kosaka Y, Chowdary JS, Xie SP, Min YM, Lee JY (2012) Limitation of seasonal predictability for summer climate over East Asia and the Northwestern Pacific. J Clim 25:7574-7589

Kosaka Y, Xie SP, Lau NC, Vecchi GA (2013) Origin of seasonal predictability for summer climate over the Northwestern Pacific. Proc Natl Acad Sci USA 110(19):7574-7579

Kripalani RH, Kulkarni A (1997) Rainfall variability over south-east Asia-connections with Indian monsoon and ENSO extremes: new perspectives. Int J Climatol 17:155-1168

Kripalani RH, Kulkarni A (1999) Climatology and variability of historical Soviet snow depth data: some new perspectives in snowIndian monsoon teleconnections. Clim Dyn 15:475-489

Kripalani RH, Kulkarni A (2001) Monsoon rainfall variations and tele-connections over South and East Asia. Int J Climatol 21:603-616

Kripalani RH, Kumar P (2004) Northeast monsoon rainfall variability over South Peninsula India vis-à-vis the Indian Ocean Dipole mode. Int J Climatol 24:1267-1282

Kripalani RH, Singh SV (1993) Large-scale aspects of India-China summer monsoon rainfall. Adv Atmos Sci 10:71-84

Kripalani RH, Kulkarni A, Singh SV (1997) Association of the Indian summer monsoon with the Northern Hemisphere Mid-Latitude circulation. Int J Climatol 17:1055-1067

Kripalani RH, Kim BJ, Oh JH, Moon SE (2002) Relationship between Soviet snow and Korean rainfall. Int J Climatol 32:1313-1325

Kripalani RH, Oh JH, Kang JH, Sabade SS, Kulkarni A (2005) Extreme monsoons over East Asia: possible role of the Indian Ocean Zonal mode. Theor Appl Climatol 82:81-94

Kripalani RH, Oh JH, Chaudhari HS (2010) Delayed influence of the Indian Ocean Dipole Mode on the East Asia-West Pacific monsoon: possible mechanism. Int J Climatol 30:197-209

Krishnan R, Sugi M (2001) Baiu rainfall variability and associated monsoon teleconnections. J Meteorol Soc Jpn 79:851-860

Kulkarni A, Sabade SS, Kripalani RH (2007) Association between the extreme monsoons and the dipole mode over the Indian subcontinent. Meteorol Atmos Phys 95:255-268

Lau WKM, Kim KM (2012) The 2010 Pakistan flood and russian heat wave: teleconnection of hydrometeorological extremes. J Hydrometeorol 13:392-403
Lau KM, Wu HT (2001) Principal modes of rainfall-SST variability of the Asian summer monsoon: a reassessment of the monsoon-ENSO relationship. J Clim 14:2880-2895

Lee JY, Wang B (2014) Future change of global monsoon in the CMIP5. Clim Dyn 42:101-119

Lee JY, Wang B, Kang IS, Shukla J, Kumar A, Kug JS, Schemm JKE, Luo JJ, Yamagata T, Fu X, Alves O, Stern B, Rosati T, Park CK (2010) How are seasonal prediction skills related to models' performance on mean state and annual cycle? Clim Dyn 35:267-283

Lee JY, Wang B, Ding Q, Ha KJ, Ahn HB, Stern B, Alves O (2011a) How predictable is the Northern Hemisphere summer upper-tropospheric circulation? Clim Dyn 37:1189-1203

Lee SS, Lee JY, Ha KJ, Wang B, Schemm J (2011b) Deficiencies and possibilities for long-lead coupled climate prediction of the Western North Pacific-East Asian summer monsoon. Clim Dyn 36(5):1173-1188. doi:10.1007/s00382-010-0832-0

Lee JY, Wang B, Wheeler MC, Fu X, Waliser DE, Kang IS (2013a) Real-time multivariate indices for the boreal summer intraseasonal oscillation over the Asian summer monsoon region. Clim Dyn 40:493-509

Lee SS, Seo YW, Ha KJ, Jhun JG (2013b) Impact of the Western North Pacific Subtropical High on the East Asian Monsoon precipitation and the Indian Ocean Precipitation in the boreal summertime. Asia Pac J Atmos Sci 49(2):171-182

Lee EJ, Ha KJ, Jhun JG (2014a) Interdecadal Changes in Interannual variability of the global monsoon precipitation and interrelationships among its subcomponents. Clim Dyn 42:2585-2601

Lee JY, Wang B, Seo KH, Kug JS, Choi YS, Kosaka Y, Ha KJ (2014b) Future change of Northern Hemisphere summer tropical-extratropical teleconnection in CMIP 5 models. J Clim 27(10):3643-3664

Lee JY, Kwon MH, Yun KS et al (2017) The long-term variability of Changma in the East Asian summer monsoon system: a review and revisit. Asia Pac J Atmos Sci 53:257-272

Li Y, Leung LR (2013) Potential impacts of the Arctic on inter-annual and inter-decadal summer precipitation over China. J Clim 26:899-917

Li T, Wang B, Zhang R (2005) East Asian-Western North Pacific monsoon: its annual cycle and subseasonal to interannual variabilities. In: Chang C-P, Wang B, Ngar-Cheung Gabriel LAU (eds) The Global Monsoon System: Research and Forecasts, Chap 8, pp 115. WMO TD No. 1266, Geneva

Li Y, Lu R, Ding B (2007) The ENSO-Asian Monsoon interaction in a coupled ocean-atmosphere GCM. J Clim 20:5164-5177. doi:10.1175/JCLI4289.1

Liu J, Wang B, Yang J (2008) Forced and internal modes of variability of the East Asian summer monsoon. Clim Past 4:225-233

Lu R, Dong B (2001) Western extension of North Pacific subtropical high in summer. J Meteorol Soc Jpn 79:1229-1241

Nitta T (1987) Convective activities in the tropical western Pacific and their impact on the Northern-Hemisphere summer circulation. J Meteorol Soc Jpn 65(3):373-390

Ogasawara T, Kawamura R (2008) Effects of combined teleconnection patterns on the East Asian summer monsoon circulation: remote forcing from low- and high-latitude regions. J Meteorol Soc Jpn 86:491-504

Preethi B, Mujumdar M, Kripalani RH, Prabhu A, Krishnan R (2016) Recent trends and tele-connections among South and East Asian summer monsoons in a warming environment. Clim Dyn. doi:10.1007/S00382-016-3218-0 (in press)

Preethi B, Mujumdar M, Prabhu A, Kripalani RH (2017) Variability and teleconnections of South and East Asian summer monsoons in present and future projections of CMIP5 climate models. Asia Pac J Atmos Sci 53:305-325 
Qian WH, Yang S (2000) Onset of the regional monsoon over Southeast Asia. Meteorol Atmos Phys 74(5):335-344

Ratnam JV et al (2010) Pacific Ocean origin for the 2009 Indian summer monsoon failure. Geophys Res Lett 37:L07807

Rayner NA, Parker DE, Horton EB, Folland CK, Alexander LV, Rowell DP, Kent EC, Kaplan A (2003) Global analyses of sea surface temperature, sea ice, and night marine air temperature since the late nineteenth century. J Geophys Res. doi:10.1029/ 2002JD002670

Roeckner E, Arpe K, Bengtsson L, Christoph M, Claussen M, D ümenil L, Esch M, Goirgetta M, Schlese U, Schulzweida U (1996) The atmospheric general circulation model ECHAM-4: model description and simulation of present-day climate. Max Planck Inst Meteorol Rep 21:90

Saji NH, Goswami BN, Vinayachandran PN, Yamagata Y (1999) A dipole mode in the tropical Indian Ocean. Nature 401:360-363

Sikka DR, Gadgil S (1980) On the maximum cloud zone and the ITCZ over the Indian Longitudes during the southwest monsoon season. Mon Weather Rev 108:1840-1853

Sun X, Greatbatch RJ, Park W, Latif M (2010) Two major modes of variability of the East Asian summer monsoon. Q J R Meteorol Soc 136:829-841

Tao SY, Chen L (1987) A review of recent research on East Asian summer monsoon in China. Chang C-P, Krishnamurti TN (eds) Monsoon meteorology. Oxford University Press, Oxford, pp 60-92

Tao SY, Zhu FK (1964) The 100-mb flow pattern in southern Asia in summer and its relation to the advance and retreat of the west Pacific subtropical anticyclone over the Far East. Acta Meteorol Sin 34:385-396 (in Chinese)

Taylor EE, Stouffer RJ, Meehl GA (2012) An overview of CIMP5 and the experiment design. Bull Am Meteorol Soc 93:485-498

Uppala SM et al (2005) The ERA-40 reanalysis. Q J R Meteorol Soc 131:2961-3012

Wang B, Ding Q (2008) Global monsoon: dominant mode of annual variation in the tropics. Dyn Atmos Oceans 44:165-183

Wang B, Fan Z (1999) Choice of South Asian summer monsoon indices. Bull Am Meteor Soc 80:629-638

Wang B, Lin H (2002) Rainy season of the Asian-Pacific summer monsoon. J Clim 15:386-396

Wang B, Wu R, Lau KM (2001) Interannual variability of the Asian Summer Monsoon: contrasts between the Indian and the Western North Pacific-East Asian monsoons. J Clim 14:4073-4090

Wang B, Clemens SC, Liu P (2003) Contrasting the Indian and East Asian monsoons: implications on geologic timescales. Mar Geol 201:5-21

Wang B, Kang IS, Lee JY (2004) Ensemble simulations of Asian-Australian monsoon variability by 11 AGCMs. J Clim 17:803-818

Wang B, Lee JY, Kang IS, Shukla J, Kug JS, Kumar A, Schemm J, Luo JJ, Yamagata T, Park CK (2008) How accurately do coupled climate models predict the leading modes of AsianAustralian monsoon interannual variability3? Clim Dyn 30:605-619

Wang B et al (2009) Advance and prospectus of seasonal prediction: assessment of APCC/CliPAS 14-model ensemble retrospective seasonal prediction (1980-2004). Clim Dyn 33:93-117

Wang Y, Liu X, Herzschuh U (2010) Asynchronous evolution of the Indian and East Asian summer monsoon indicated by Holocene moisture patterns in monsoonal central Asia. Earth Sci Rev 103:135-153
Wang H, Wang B, Huang F, Ding Q, Lee JY (2012) Interdecadal changes of the boreal summer circumglobal teleconnection (1958-2010). Geophys Res Lett 39:L12704

Wang B, Xiang B, Lee JY (2013) Subtropical High predictability establishes a promising way for monsoon and tropical storm predictions. PNAS 110(8):2718-2722

Wang B, Yim SY, Lee JY, Liu J, Ha KJ (2014) Future change of Asian-Australian monsoon under RCP 4.5 Anthropogenic warming scenario. Clim Dyn 42:83-100

Wang B, Lee JY, Xiang B (2015) Asian summer monsoon rainfall predictability: a predictable mode analysis. Clim Dyn 14(1):61-74

Watanabe M, Shiogama H, Imada Y, Mori M, Ishii M, Masahide K (2013) Event attribution of the August 2010 Russian Heat Wave. SOLA 9:65-68

Webster M, Sokolov A, Reilly J, Forest C, Paltsev S, Schlosser A, Wang C, Kicklighter D, Sarofim M, Melillo J, Prinn R, Jacoby H (2012) Analysis of climate policy targets under uncertainty. Clim Change 112:569-583

Wei W, Zhang R, Wen M, Rong X, Li T (2014) Impact of Indian summer monsoon on the South Asian High and its influence on summer rainfall over China. Clim Dyn 43:1257-1269

Wu R (2002) A mid-latitude Asian circulation anomaly pattern in boreal summer and its connection with Indian and East Asian summer monsoons. Int J Climatol 22:1879-1895

Wu R (2017) Relationship between Indian and East Asia summer rainfall variations. Adv Atmos Sci 34(1):4-15. doi:10.1007/ s00376-016-6216-6

Wu R, Kirtman BP (2007) Regimes of seasonal air-sea interaction and implications for performance of forced simulations. Clim Dyn 29(4):393-410, doi:10.1007/s00382-007-0246-9

Wu R, Wang B (2002) A contrast of the East Asian summer monsoon-ENSO relationship between 1962-77 and 1978-93. J Clim 15:3266-3279

Wu R, Hu ZZ, Kirtman BP (2003) Evaluation of ENSO-related rainfall anomalies in East Asia. J Clim 16:3742-3758

Xie P, Arkin PA (1997) Global precipitation: a 17-year monthly analysis based on gauge observations, satellite estimates, and numerical model outputs. Bull Am Meteorol Soc 79(11):2539-2558

Yun KS, Seo KH, Ha KJ (2008) Relationship between ENSO and northward propagating intraseasonal oscillation in the East Asian summer monsoon system. J Geophys Res 113:D14120. doi:10.1029/2008JD009901

Yun KS, Seo KH, Ha KJ (2010) Interdecadal change in the relationship between ENSO and the intraseasonal oscillation in East Asia. J Clim 23:3599-3612. doi:10.1175/2010JCLI3431.1

Yun KS, Lee JY, Ha KJ (2014) Recent intensification of the South and East Asian monsoon contrast associated with an increase in the zonal tropical SST gradient. J Geophys Res Atmos. doi:10.1 002/2014JD021692

Zhang R (1999) The role of Indian summer monsoon water vapor transportation on the summer rainfall anomalies in the northern part of China during the El Niño mature phase. Plateau Meteorol 18:567-574 (in Chinese)

Zhang R (2001) Relation of water vapor transport from the Indian monsoon with that over East Asia and the summer rainfall in China. Adv Atmos Sci 18:1005-1017

Zhu Q, He J, Wang P (1986) A study of circulation differences between East-Asian and Indian summer monsoons with their interaction. Adv Atmos Sci 3:466-477 